Cochrane Database of Systematic Reviews

\title{
Carotid endarterectomy for symptomatic carotid stenosis (Review)
}

Rerkasem A, Orrapin S, Howard DPJ, Rerkasem K

Rerkasem A, Orrapin S, Howard DPJ, Rerkasem K.

Carotid endarterectomy for symptomatic carotid stenosis.

Cochrane Database of Systematic Reviews 2020, Issue 9. Art. No.: CD001081.

DOI: 10.1002/14651858.CD001081.pub4.

www.cochranelibrary.com 
TABLE OF CONTENTS

ABSTRACT 1

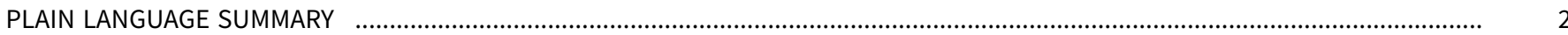

SUMMARY OF FINDINGS

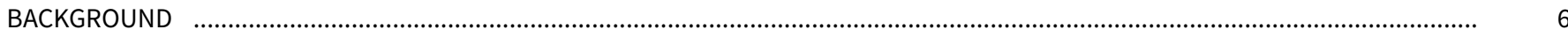

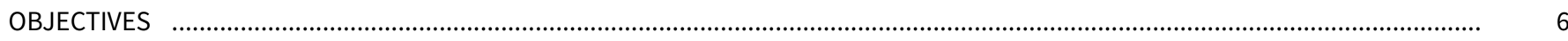

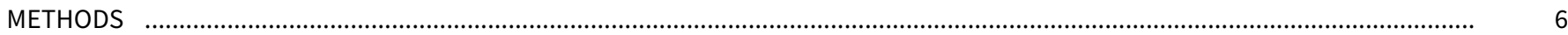

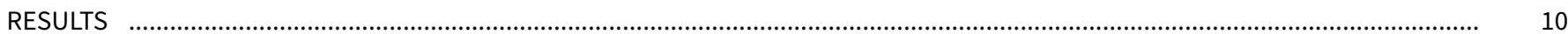

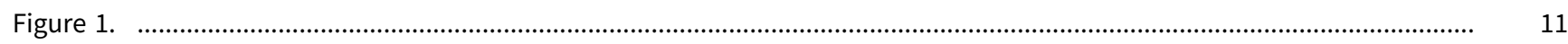

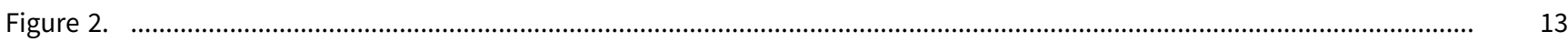

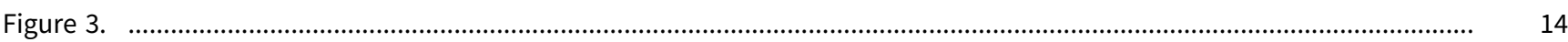

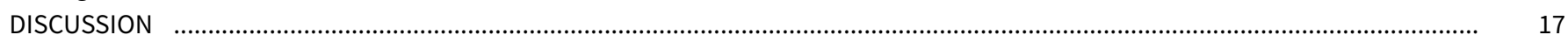

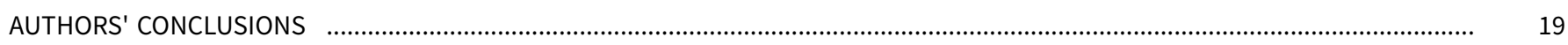

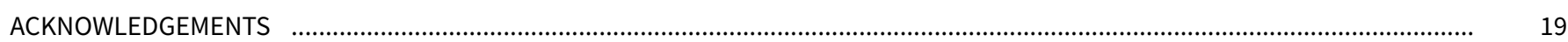

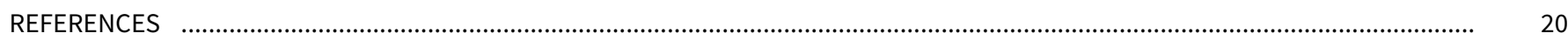

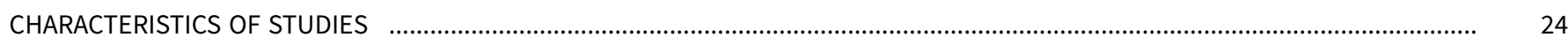

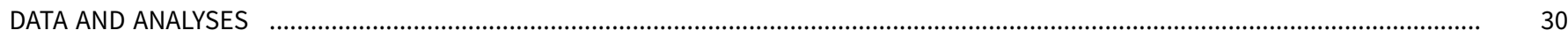

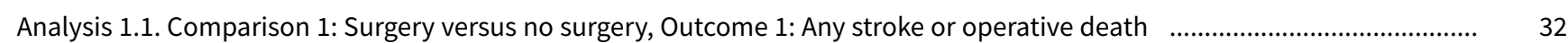

Analysis 1.2. Comparison 1: Surgery versus no surgery, Outcome 2: Ipsilateral ischaemic stroke and any operative stroke or 33 death

Analysis 1.3. Comparison 1: Surgery versus no surgery, Outcome 3: Disabling or fatal ipsilateral ischaemic or operative stroke and death

Analysis 2.1. Comparison 2: Subgroup analyses (5-year cumulative risk of ipsilateral carotid ischaemic stroke, and any stroke or death within 30 days after surgery, according to 3 variables in patients with $>50 \%$ carotid stenosis in ECST and NASCET), Outcome 1: Sex

Analysis 2.2. Comparison 2: Subgroup analyses (5-year cumulative risk of ipsilateral carotid ischaemic stroke, and any stroke or death within 30 days after surgery, according to 3 variables in patients with $>50 \%$ carotid stenosis in ECST and NASCET), Outcome 2: Age (years)

Analysis 2.3. Comparison 2: Subgroup analyses (5-year cumulative risk of ipsilateral carotid ischaemic stroke, and any stroke or death within 30 days after surgery, according to 3 variables in patients with $>50 \%$ carotid stenosis in ECST and NASCET), Outcome 3: Time since last event (weeks)

ADDITIONAL TABLES

APPENDICES

WHAT'S NEW

HISTORY

CONTRIBUTIONS OF AUTHORS

DECLARATIONS OF INTEREST

SOURCES OF SUPPORT

INDEX TERMS 
[Intervention Review]

\section{Carotid endarterectomy for symptomatic carotid stenosis}

Amaraporn Rerkasem¹, Saritphat Orrapin², Dominic PJ Howard³ ${ }^{3}$ Kittipan Rerkasem ${ }^{1,4}$

${ }^{1}$ Research Institute for Health Sciences, Chiang Mai University, Chiang Mai, Thailand. 2Division of Vascular Surgery, Department of Surgery, Faculty of Medicine, Thammasat University (Rangsit Campus), Pathum thani, Thailand. ${ }^{3}$ Centre for Prevention of Stroke and Dementia, Nuffield Department of Clinical Neurosciences, University of Oxford, Oxford, UK. ${ }^{4}$ Division of Vascular and Endovascular Surgery, Department of Surgery, Faculty of Medicine, Chiang Mai University, Chiang Mai, Thailand

Contact: Kittipan Rerkasem, rerkase@gmail.com.

Editorial group: Cochrane Stroke Group.

Publication status and date: New search for studies and content updated (no change to conclusions), published in Issue 9, 2020.

Citation: Rerkasem A, Orrapin S, Howard DPJ, Rerkasem K. Carotid endarterectomy for symptomatic carotid stenosis. Cochrane Database of Systematic Reviews 2020, Issue 9. Art. No.: CD001081. DOI: 10.1002/14651858.CD001081.pub4.

Copyright @ 2020 The Cochrane Collaboration. Published by John Wiley \& Sons, Ltd.

\section{A B S T R A C T}

\section{Background}

Stroke is the third leading cause of death and the most common cause of long-term disability. Severe narrowing (stenosis) of the carotid artery is an important cause of stroke. Surgical treatment (carotid endarterectomy) may reduce the risk of stroke, but carries a risk of operative complications. This is an update of a Cochrane Review, originally published in 1999, and most recently updated in 2017.

\section{Objectives}

To determine the balance of benefit versus risk of endarterectomy plus best medical management compared with best medical management alone, in people with a recent symptomatic carotid stenosis (i.e. transient ischaemic attack (TIA) or non-disabling stroke).

\section{Search methods}

We searched the Cochrane Stroke Group Trials Register, CENTRAL, MEDLINE Ovid, Embase Ovid, Web of Science Core Collection, ClinicalTrials.gov, and the WHO International Clinical Trials Registry Platform (ICTRP) portal to October 2019. We also reviewed the reference lists of all relevant studies and abstract books from research proceedings.

\section{Selection criteria}

We included randomised controlled trials (RCTs) comparing carotid artery surgery plus best medical treatment with best medical treatment alone.

\section{Data collection and analysis}

Two review authors independently selected studies, assessed risk of bias, and extracted the data. We assessed the results and the quality of the evidence of the primary and secondary outcomes by the GRADE method, which classifies the quality of evidence as high, moderate, low, or very low.

\section{Main results}

We included three trials involving 6343 participants. The trials differed in the methods of measuring carotid stenosis and in the definition of stroke. Using the primary electronic data files, we pooled and analysed individual patient data on 6092 participants (35,000 patientyears of follow-up), after reassessing the carotid angiograms and outcomes from all three trials, and redefining outcome events where necessary, to achieve comparability.

Surgery increased the five-year risk of any stroke or operative death in participants with less than $30 \%$ stenosis (risk ratio (RR) 1.25 , 95\% confidence interval (Cl) 0.99 to 1.56; 2 studies, 1746 participants; high-quality evidence). Surgery decreased the five-year risk of any 
stroke or operative death in participants with $30 \%$ to $49 \%$ stenosis (RR $0.97,95 \% \mathrm{Cl} 0.79$ to $1.19 ; 2$ studies, 1429 participants; high-quality evidence), was of benefit in participants with $50 \%$ to $69 \%$ stenosis (RR $0.77,95 \% \mathrm{Cl} 0.63$ to $0.94 ; 3$ studies, 1549 participants; moderatequality evidence), and was highly beneficial in participants with $70 \%$ to $99 \%$ stenosis without near-occlusion (RR $0.53,95 \% \mathrm{Cl} 0.42$ to 0.67 ; 3 studies, 1095 participants; moderate-quality evidence). However, surgery decreased the five-year risk of any stroke or operative death in participants with near-occlusions (RR 0.95, 95\% Cl 0.59 to 1.53; 2 studies, 271 participants; moderate-quality evidence).

\section{Authors' conclusions}

Carotid endarterectomy reduced the risk of recurrent stroke for people with significant stenosis. Endarterectomy might be of some benefit for participants with $50 \%$ to $69 \%$ symptomatic stenosis (moderate-quality evidence) and highly beneficial for those with $70 \%$ to $99 \%$ stenosis (moderate-quality evidence).

\section{PLAIN LANGUAGE SUMMARY}

\section{Carotid surgery in people who have symptoms with narrowing of the carotid artery}

\section{Question}

What are the benefits of surgical removal of the fatty deposits and blood clots from inside the carotid artery wall (carotid endarterectomy) for people who have recently (within four to six months) had symptoms due to carotid stenosis (narrowing of the artery that supplies blood to the brain)?

\section{Background}

Strokes cause long-term disability and death. The chances of dying from the first stroke are $15 \%$ to $35 \%$, and increase to $69 \%$ in subsequent strokes, which often occur within one year of the first attack. Carotid endarterectomy may reduce the risk of subsequent or recurrent stroke, but carries a risk of complications immediately before, after, and during the operation, including disabling stroke and death. There is a $7 \%$ risk of stroke and death within 30 days of endarterectomy.

\section{Search date}

We searched for studies to 23 October 2019.

\section{Study characteristics}

This review identified three randomised controlled trials (6343 participants randomised), which compared carotid surgery with no carotid surgery (i.e. best medical therapy plus surgery versus best medical therapy alone) in participants with carotid stenosis and recent transient ischaemic attacks (TIA), or minor ischaemic strokes in the territory of that artery. The trials were carried out in centres in Europe, USA, Canada, Israel, South Africa, and Australia. The gender ratio of participants was $2.6: 1$ ( $72 \%$ men and $28 \%$ women); $90 \%$ of participants were younger than 75 years old.

The results of the three trials were initially conflicting, because they differed in how they measured carotid stenosis and how they defined the outcomes. To address this discrepancy, we reassessed the original patient data using the same methods and definitions, so results could be compared.

\section{Key results}

Carotid endarterectomy reduced the risk of further stroke for people with significant stenosis. Results were particularly striking for older people, male participants, those with a significant stenosis (70\% to 99\%), and those who were operated on within two weeks of their TIA or stroke. Endarterectomy might be of some benefit for participants with $50 \%$ to $69 \%$ stenosis. We did not find any benefit of carotid surgery for those in whom the stenosis was minor (less than 50\%) or where the carotid artery was almost blocked (near occlusion).

\section{Quality of the evidence}

The evidence was of moderate or high quality for all the results. Therefore, we can be moderately or very confident in the results. 
SUMMARY OF FINDINGS

Summary of findings 1. Carotid endarterectomy for symptomatic carotid stenosis

Carotid endarterectomy for symptomatic carotid stenosis

Patients or population: people with carotid stenosis and recent transient ischaemic attacks (TIA) or minor ischaemic strokes in the territory of that artery Settings: hospitals with carotid centres ${ }^{a}$

Intervention: best medical therapy with carotid surgeryb,c

Comparison: best medical therapy without carotid surgery $b$

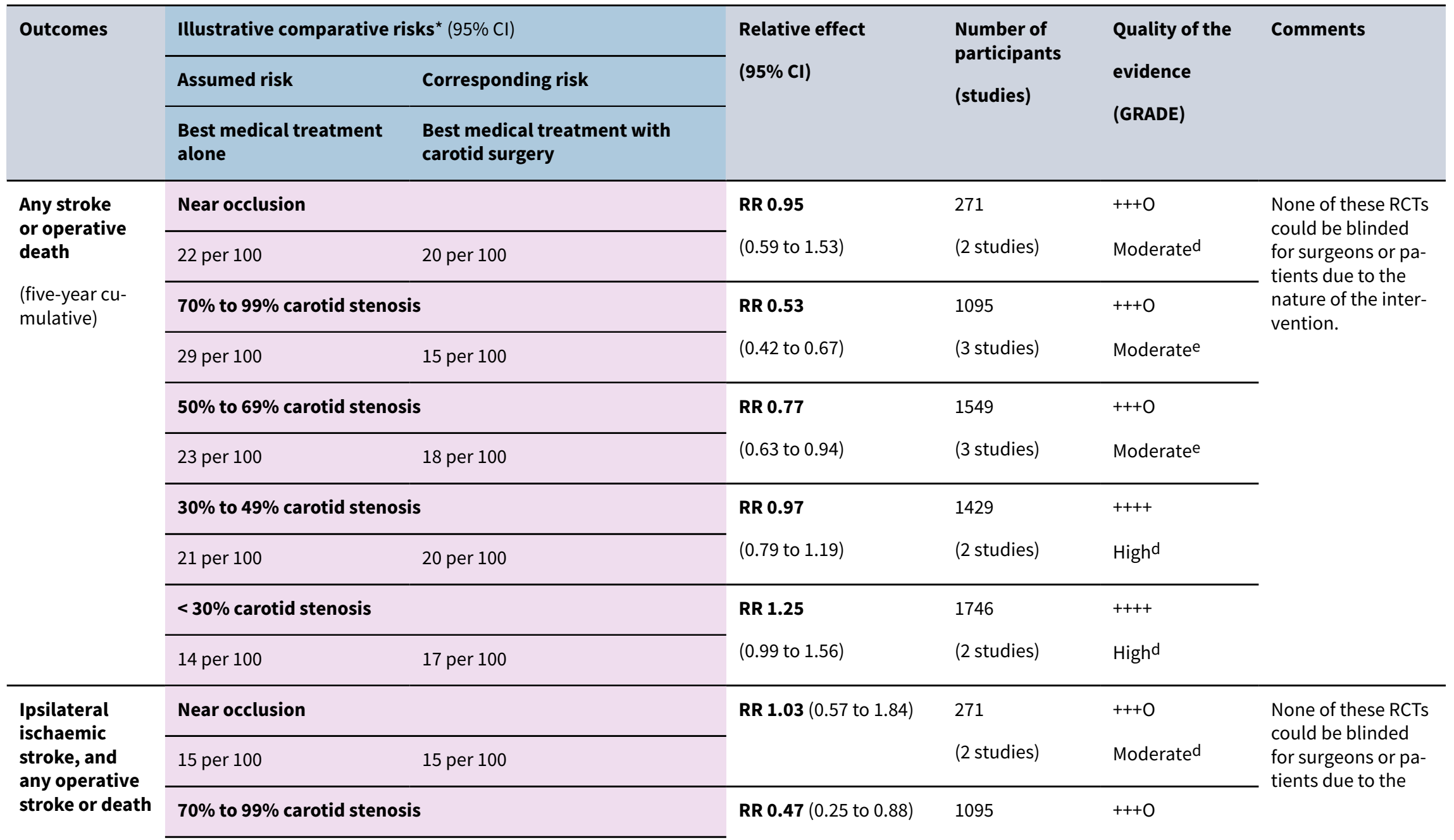




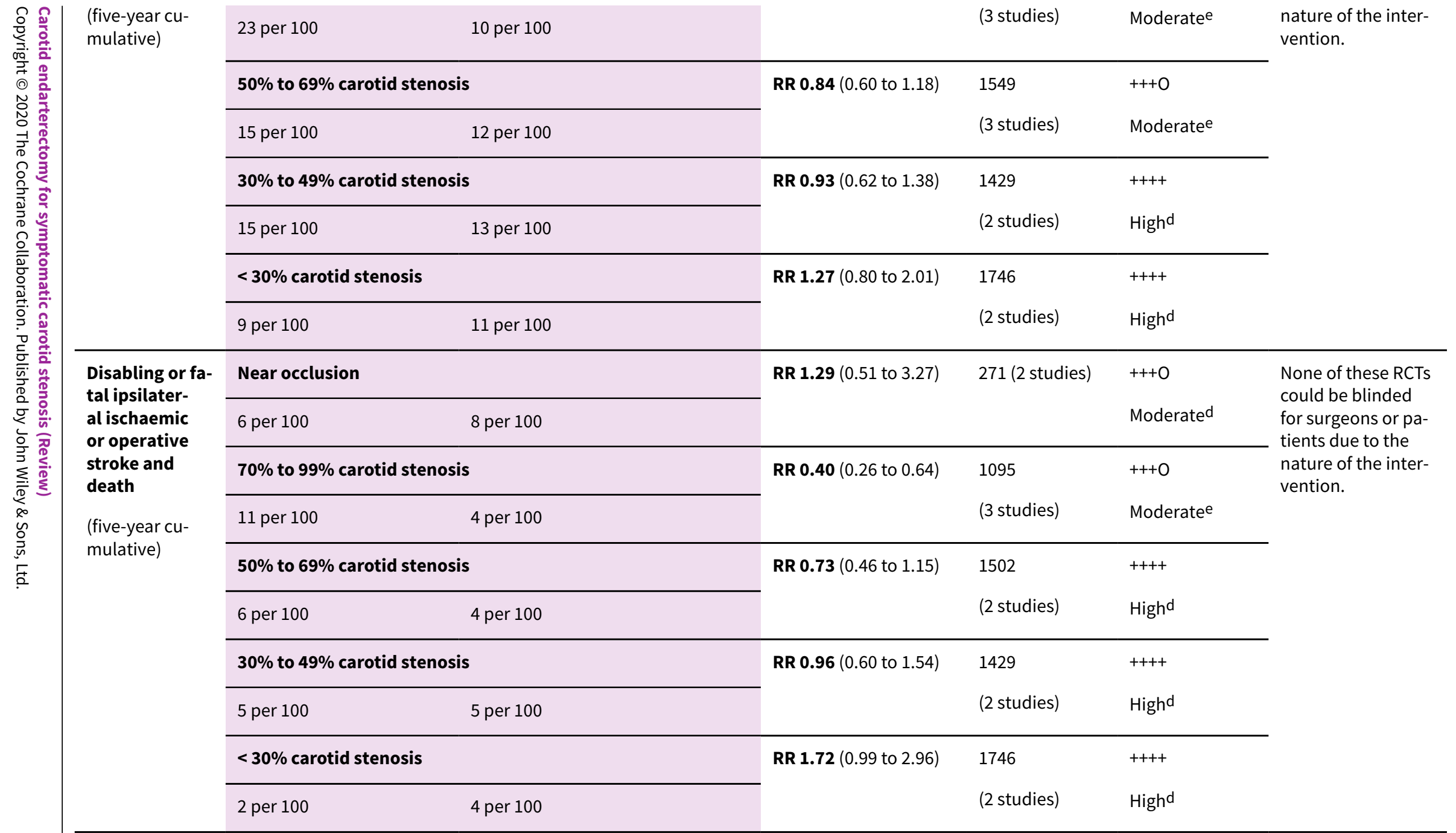

${ }^{\star}$ The basis for the assumed risk is provided in footnotes. The corresponding risk (and its $95 \%$ confidence interval) is based on the assumed risk in the intervention group and the relative effect of the intervention (and its $95 \% \mathrm{Cl}$ ).

$\mathrm{Cl}$ : confidence interval; RR: risk ratio

\section{GRADE Working Group grades of evidence}

High certainty. We are very confident that the true effect lies close to that of the estimate of the effect.

Moderate certainty. We are moderately confident in the effect estimate; the true effect is likely to be close to the estimate of the effect, but there is a possibility that it is substantially different.

Low certainty. Our confidence in the effect estimate is limited; the true effect may be substantially different from the estimate of the effect. 
a ECST 1998 recruited from 100 centres in 14 European countries, NASCET 1991 from 106 centres mainly in the USA and Canada, with some centres in Europe, Israel, South Africa and Australia, and VACSP 1991 from 16 Veterans Affairs medical centres in the USA

bThe recommended dose of aspirin for best medical treatment was $1300 \mathrm{mg}$ in NASCET 1991, $325 \mathrm{mg}$ in VACSP 1991, and unspecified in ECST 1998

CThe median time from randomisation to trial surgery was two days in VACSP 1991, three days in NASCET 1991, and 14 days in ECST 1998.

$\mathrm{d}$ Both studies were unconfounded, truly randomised controlled trials and were conducted on an intention-to-treat principle with adequate concealment, Few patients were lost to follow-up in any of these studies (follow-up $99.8 \%$ to $100 \%$ ). However, for the outcome in patients with near occlusion lesion, we downgraded one level because the numbers of participants and outcome events were small.

eAll 3 studies were unconfounded, truly randomised controlled trials and conducted on an intention-to-treat principle. However, the allocation concealment was not described in VACSP 1991. In addition, VACSP 1991 was stopped with 193 participants after the results of ECST 1998 and NASCET 1991 were published, given that it was considered unethical to continue to randomise participants with severe stenosis. This sequence of events may have introduced bias into the results. Thus, the outcomes involving VACSP 1991 were downgraded one level to moderate-quality evidence because the limitations in the implementation of available studies suggested a high likelihood of bias due to potential bias by VACSP 1991.

\section{Underlying methodology}

\section{Quality rating}

Randomised trials or double-upgraded observational studies: high

Downgraded randomised trials or upgraded observational studies: moderate

Double-downgraded randomised trials or observational studies: low

Triple-downgraded randomised trials, or downgraded observational studies, or case series/case reports:

- limitations in the design and implementation of available studies suggesting high likelihood of bias;

- indirectness of evidence (indirect population, intervention, control, outcomes);

- unexplained heterogeneity or inconsistency of results (including problems with subgroup analyses);

- imprecision of results (wide confidence intervals);

- high probability of publication bias. 


\section{B A C K G R O U N D}

\section{Description of the condition}

Stroke is the third leading cause of death, and probably the most important cause of long-term disability (Bonita 1992). The case fatality rate is between $15 \%$ and $35 \%$ with the first attack, and rises to $65 \%$ for subsequent strokes. The majority of recurrences occur within one year, and in the same anatomic region as the first stroke (Mohr 1978; Sacco 1982; Soltero 1978). Disability in survivors is a burden to the patients, their families, and to society. Eightyfive per cent of strokes are ischaemic (Bamford 1990). Fieschi 1989 found that in conscious people with an acute ischaemic stroke requiring admission to a stroke unit, $76 \%$ had angiographic evidence of complete occlusion of the internal carotid artery, the middle cerebral artery, or one of its branches. The majority of these occlusions were thought to be embolic, and of cerebrovascular origin.

\section{Description of the intervention}

Atherosclerotic plaques can rupture and lead to thrombosis and emboli, which can cause stroke if they occur in a carotid artery (Eliasziw 1994). Carotid endarterectomy is a surgical procedure to remove the endothelium and atherosclerotic plaque from inside the carotid artery wall. This has been proven to reduce the risk of stroke in certain groups of people. Two techniques have been described for carotid endarterectomy. In a standard endarterectomy, the most popular technique, carotid plaque is removed by a longitudinal arteriotomy. An eversion endarterectomy is performed through an oblique transection of the internal carotid artery from the common carotid artery, the plaque is removed by eversion of the internal carotid artery, and the internal carotid artery is reimplanted on the common carotid artery.

\section{How the intervention might work}

As previously stated, atherosclerotic plaque can cause embolic stroke. Since carotid endarterectomy removes plaque from the carotid artery, the source of a cerebral embolism is also removed. In addition, the procedure removes the stenotic part of the carotid artery, so blood flow to the brain can be increased.

\section{Why it is important to do this review}

Carotid endarterectomy was introduced in the 1950 s and increasing numbers of people have undergone this procedure over the last three decades - from 14,000 performed in the USA in 1971 to 107,000 in 1985 (Pokras 1988). In 1985, the Extracranial/Intracranial (EC/IC) Bypass Study showed no benefit for this form of surgery, increasing uncertainties about the value of carotid endarterectomy (EC/IC Bypass 1985). By 1989, the number of carotid endarterectomies performed in North America had declined to 70,000 (Dyken 1993; Hsia 1992). These uncertainties led to large randomised controlled trials assessing the efficacy of the procedure in different clinical settings.

There have been five randomised controlled trials of endarterectomy in people with a recent symptomatic carotid stenosis. The first two studies were small, performed over 30 years ago, included a high proportion of people with noncarotid symptoms, and did not stratify results by severity of the stenosis (Fields 1968; Shaw 1984). In 1991, the Veterans Affairs trial reported a non-significant trend in favour of surgery (VACSP 1991), but this trial was stopped early when the two largest trials, the European Carotid Surgery Trial (ECST 1998), and the North American Symptomatic Carotid Endarterectomy Trial (NASCET 1991), reported their initial results. The final reports for ECST 1998 and NASCET 1991 were published in 1998. ECST 1998 reported benefit from surgery only in participants with $80 \%$ to $99 \%$ stenosis, and further limited this to $90 \%$ to $99 \%$ stenosis in women. In contrast, NASCET 1991 reported significant benefit from surgery in participants with $50 \%$ to $99 \%$ stenosis. In an earlier version of this review, an attempt was made to reconcile and pool these apparently conflicting results (Rerkasem 2011). The differences between the trial results were partly due to differences in the methods of measurement of the degree of carotid stenosis on the pre-randomisation catheter angiograms: the method used in ECST 1998 produced higher values than the method used in the NASCET 1991 and VACSP 1991 trials. There were also other differences, such as in the definitions of outcome events. Only by detailed re-analysis of the individual patient data and reassessment of the original angiograms can the results be properly compared or combined. In the 2017 version of the review, we also included a pooled analysis of individual patient data from the three largest trials, in which we reassessed and analyses the original angiograms, using the same method of measurement of stenosis and the same definitions of outcomes (Orrapin 2017).

However, the overall trial results may not help patients and clinicians to make decisions about surgery. It would be useful to be able to identify in advance, and only operate on those people with a high risk of stroke on medical treatment alone, but relatively low operative risk. In addition to the degree of carotid stenosis, there are several other factors that might influence the risks and benefits of surgery, including the delay between presenting symptoms and surgery, and certain clinical and angiographic characteristics (Alamowitch 2001; Benavente 2001; Eliasziw 1994; Henderson 2000; Kappelle 1999; Morgenstern 1997; Rothwell 1997; Rothwell 1999). Neither ECST 1998 nor NASCET 1991 were powered to determine the effect of surgery in subgroups. Subgroup analyses of pooled individual patient data from ECST 1998 and NASCET 1991 have greater power to determine subgroup treatment interaction reliably, and therefore, we added several such clinically important analyses in the Orrapin 2017 version.

\section{O B JECTIVES}

To determine the balance of benefit versus risk of endarterectomy plus best medical management compared with best medical management alone, in people with a recent symptomatic carotid stenosis (i.e. transient ischaemic attack (TIA) or non-disabling stroke).

\section{METHODS}

\section{Criteria for considering studies for this review}

\section{Types of studies}

We included randomised controlled trials (RCTs).

\section{Types of participants}

People with carotid stenosis and recent transient ischaemic attacks (TIA) or minor ischaemic strokes in the territory of that artery. 


\section{Types of interventions}

Unconfounded comparison of carotid surgery with no carotid surgery (i.e. best medical therapy plus surgery versus best medical therapy alone).

\section{Types of outcome measures}

\section{Primary outcomes}

- Five-year cumulative any stroke or operative death.

- Five-year cumulative ipsilateral ischaemic stroke, or operative stroke, or operative death.

The five-year cumulative risk is the summative risk of all participants between recruitment and index outcome over five years.

We defined trial surgery as the first carotid endarterectomy performed in participants who were randomised to surgery. We defined operative risk as any stroke or death that occurred within 30 days of trial surgery. Operative death included all deaths within 30 days of trial surgery. We defined the symptomatic carotid artery as in the original trials.

Ipsilateral ischaemic stroke describes insufficient blood flow to the cerebral hemisphere secondary to the same side occlusion, or severe stenosis of the internal carotid artery.

\section{Secondary outcomes}

- Five-year cumulative disabling or fatal ipsilateral ischaemic, or operative stroke, and operative death.

\section{Search methods for identification of studies}

See the methods for the Cochrane Stroke Group Specialised register. We did not use any language restrictions in the searches; we arranged translation of all possibly relevant publications where necessary.

\section{Electronic searches}

We searched the Cochrane Stroke Group's Trials Register, which was last searched by the Managing Editor in October 2019. In addition, we searched the Cochrane Central Register of Controlled Trials (CENTRAL; 2019, Issue 10 of 12) in the Cochrane Library (searched 23 October 2019; Appendix 1), MEDLINE Ovid (1966 to 23 October 2019; Appendix 2), and Embase Ovid (1980 to 23 October 2019; Appendix 3). We also searched the Web of Science Core Collection (last searched 23 October 2019; Appendix 4).

The subject strategies for databases were modelled on the search strategy designed for MEDLINE in Appendix 1, by the Cochrane Stroke Group's Information Specialist. All search strategies deployed were combined with subject strategy adaptations of the highly sensitive search strategy designed by Cochrane for identifying RCTs and controlled clinical trials, as described in the Cochrane Handbook for Systematic Reviews of Interventions (Higgins 2019)

Having identified the two major studies in this area, we used a post-hoc search strategy of ECST (text word) or European Carotid Surgery Trial (text word) or NASCET (text word) or North American Symptomatic Carotid Endarterectomy Trial (text word) in the CENTRAL and in the MEDLINE Ovid database from 1990 to 23
October 2019, in the hope of identifying previously unretrieved publications from these trials.

\section{Searching other resources}

In an effort to identify further published, unpublished, and ongoing trials, we:

- searched ClinicalTrials.gov and the World Health Organization International Clinical Trials Registry Platform (apps.who.int/ trialsearch; last searched 23 October 2019: Appendix 4); and

- reviewed the reference lists of all relevant studies and abstract books in research proceedings.

\section{Data collection and analysis}

Two review authors (AR, SO) independently collected data. We collected the details of methods, participants, setting, context, interventions, outcomes, results, publications, and investigators. We performed meta-analysis using Review Manager 5 (RevMan 5; Review Manager 2014).

\section{Selection of studies}

Two review authors (AR, SO) independently read the titles and abstracts of the records obtained from the electronic searches and excluded obviously irrelevant studies. We obtained the full texts of the remaining papers, and the same authors independently selected studies for inclusion, based on the predefined criteria. We resolved any disagreements through discussion. One review author (AR) selected those trials that met the inclusion criteria and another review author (SO) independently reviewed these decisions. We resolved all disagreements through discussion with other review authors (DPH, KR).

\section{Data extraction and management}

We extracted details of the method of randomisation, the blinding of outcome assessments, losses to follow-up, and crossovers and exclusions after randomisation from the publications. We also extracted participant characteristics (age, sex, vascular risk factors, indication for surgery) and details of the operation (type of cerebral monitoring, use of carotid patching, anaesthetic technique, use of perioperative antiplatelet therapy). One review author (AR) extracted those trials that were selected and another review author (SO) independently reviewed these decisions. We resolved all disagreements through discussion with other review authors (DPH, $\mathrm{KR})$.

\section{Assessment of risk of bias in included studies}

One review author (SO) assessed the risk of bias and another review author (KR) independently reviewed these decisions. We resolved all disagreements through discussion. We assessed risk of bias (high risk, low risk, unclear risk) using the Cochrane 'Risk of bias' tool as described in the Cochrane Handbook for Systematic Reviews of Interventions and reported the details in the 'Risk of bias' tables (Higgins 2019). These risks of bias included random sequence generation (selection bias), allocation concealment (selection bias), blinding of participants and personnel (performance bias), blinding outcome assessment (detection bias), and incomplete outcome data (attrition bias). 


\section{Measures of treatment effect}

We measured the treatment effect in the following outcomes within five years of randomisation: stroke, death, ipsilateral ischaemic stroke, disabling or fatal ipsilateral ischaemic stroke, stroke and death within 30 days after carotid endarterectomy.

\section{Unit of analysis issues}

We extracted details of all outcome events. Some studies included participants who had bilateral operations, but only reported the number of participants in each group, and not the number of arteries. Unit of analysis issues originate when bilateral carotid arteries for the same participants are studied in a trial and such highly correlated data are regarded as independent, when multiple assessments of the same outcome are presented, or both. We recorded whether trials presented outcomes in relation to an artery, a participant, or as multiple (bilateral) carotid arteries for the same participant.

When a cluster-randomised trial has been conducted and correctly analysed, effect estimates and their standard errors may be metaanalysed using the generic inverse variance method in RevMan 5 (Review Manager 2014). If the randomisation was performed on the clusters rather than the individuals, we approximated the correct analyses using data suggested in the Cochrane Handbook for Systematic Reviews of Interventions (Higgins 2019):

- the number of clusters (or groups) randomised to each intervention group, or the average (mean) size of each cluster;

- the outcome data, ignoring the cluster design, for the total number of individuals (for example, number or proportion of individuals with events, or means and standard deviations); and

- an estimate of the intracluster (or intraclass) correlation coefficient (ICC).

\section{Dealing with missing data}

When data were missing, we contacted the corresponding author or co-author through the address given in the publication. If this information was not available, we searched for the study group via the Internet, and contacted them for missing information.

\section{Assessment of heterogeneity}

We assessed heterogeneity between study results using the $\mathrm{I}^{2}$ statistic (Higgins 2003). We examined the percentage of total variations across the studies due to heterogeneity, rather than to chance.

We used $I^{2}$ results for quantifying inconsistency across studies. Values of $\mathrm{I}^{2}$ over $0 \%$ indicated a considerable level of heterogeneity and were investigated.

\section{Assessment of reporting biases}

We performed an extensive search, and are confident that we identified all major relevant trials. We also contacted experts in this field. We searched for trials published in all languages, and we arranged translation of all possibly relevant publications when required. We had planned to use funnel plots to assess publication bias when more than 10 studies were included (Sterne 2011). However, if there were insufficient studies to conduct this analysis, we had planned to compare the study protocols with the final study reports to evaluate selective reporting of outcomes.

\section{Data synthesis}

We included all participants included in the final analysis of the results of the original trials in the combined analysis, using the Mantel-Haenszel method (fixed-effect). We stratified the main analyses according to the stenosis groups that were used in the NASCET 1991 trial (less than 30\%, 30\% to 49\%, 50\% to 69\%, 70\% to 99\%), and analysed near-occlusions separately (Rothwell 2003).

We performed all analyses of the effect of surgery on an intentionto-treat basis, according to the randomised treatment allocation. We assessed significance of the differences between treatment groups by the log rank test, stratified by study. We determined estimates of the absolute treatment effect (and 95\% confidence intervals) at five-year follow-up from the Kaplan-Meier event-free survival curves. We tested significance of the differences in baseline data between trials and treatment groups using the $\mathrm{Chi}^{2}$ test or Student's t-test, as appropriate. We used RevMan 5 software (Review Manager 2014), and SPSS for Windows version 10.0 for all analyses (SPSS 1999). We used the fixed-effect model for metaanalysis in the absence of clinical, methodological, and statistical heterogeneity. If the $I^{2}$ statistic was greater than $0 \%$, we also applied a random-effects model to see whether the conclusions differed, and we noted any difference. If pooling was not possible or appropriate, we had planned to present a narrative summary (Deeks 2011).

\section{GRADE and 'Summary of findings' table}

We created Summary of findings 1 with GRADEpro GDT (GRADEpro GDT), which imports data from RevMan 5. This table presents the results and the quality of the evidence of the main outcomes, using the GRADE system, which classifies the quality of evidence as high, moderate, low, and very low (Schünemann 2011). We included three main outcomes in this table: 1) any stroke or operative death, 2) Ipsilateral ischaemic stroke, and any operative stroke or death, 3) disabling or fatal ipsilateral ischaemic or operative stroke and death.

\section{Pooling of individual patient data}

We obtained the original individual patient data for the three included trials. We merged data on presenting events; baseline clinical, brain imaging, and angiographic characteristics; surgical and anaesthetic technique; and follow-up into a single composite database. We gave detailed consideration to the definitions of each variable used in the original trials. Where definitions were identical, we merged comparable data. Where possible, we resolved differences in definitions of variables between studies by reconstructing definitions to achieve comparability.

\section{Reassessment of carotid angiograms and identification of near-occlusions}

We collected all ECST 1998 and NASCET 1991 pre-randomisation angiograms and reviewed them centrally for a previous version of this review (Rerkasem 2011). Therefore, the analyses could be consistently stratified by the degree of symptomatic carotid stenosis. As the first version of this review was performed without reclassifying angiograms, it was difficult to compare the results between studies (ECST 1998; NASCET 1991; VACSP 1991). This was due to different grading of the carotid stenosis used by the trials. One observer, who was blind to outcome events, re-measured the 3018 ECST 1998 angiograms, and re-calculated the degree 
of stenosis using the method used in NASCET 1991 and VACSP 1991. The NASCET 1991 method was based on measurement of the minimum residual lumen at the point of maximum stenosis and the diameter of the normal internal carotid artery well beyond the carotid bulb, where the walls of the artery were parallel. We assessed observer agreement between one observer and the NASCET 1991 principal neuroradiologist on 120 randomly selected angiograms (60 from ECST 1998 and 60 from NASCET 1991).

The degree of stenosis could not be calculated by the method used in the NASCET 1991 and VACSP 1991 trials on angiograms, in which the post-stenotic internal carotid artery (ICA) was narrowed to the point of near occlusion. In the original NASCET 1991 reports, these 'near-occlusions' were identified and assigned as 95\% stenosis for the purpose of analysis. Therefore, we identified near-occlusions during the reassessment of the ECST 1998 angiograms for this review. We used the previously reported NASCET 1991 angiographic criteria for near-occlusion: severe stenosis with evidence of reduced flow in the distal ICA (delayed arrival of contrast into the distal ICA, or evidence of collateral flow of contrast towards the symptomatic cerebral hemisphere from other arterial territories, or both) and evidence of narrowing of the post-stenotic ICA (lumen diameter similar to, or less than, the ipsilateral external carotid artery, and less than the contralateral ICA). To ensure comparability with NASCET 1991, the NASCET 1991 principal neuroradiologist assessed all potential near-occlusions identified in ECST 1998. The VACSP 1991 trial angiograms were not available for further review, and were not included in the analysis of near-occlusions. For the purpose of analysis, all VACSP 1991 trial angiograms with stenosis of $70 \%$ or more were considered to have stenosis of $70 \%$ or more without near-occlusion.

\section{Redefinition of outcome events}

In the NASCET 1991 and VACSP 1991 trials, a stroke outcome was defined as a cerebrovascular event with symptoms lasting longer than 24 hours. ECST 1998 recorded all such events, but confined analysis to events with symptoms that lasted for at least seven days. In the NASCET 1991 and VACSP 1991 trials, retinal infarcts were included as stroke outcomes. In ECST 1998, they were not, although they were recorded. For the purpose of the combined analyses, we defined stroke as any cerebral or retinal event with symptoms lasting longer than 24 hours. ECST 1998 and NASCET 1991 used the modified Rankin Scale to define disabling stroke. VACSP 1991 used an equivalent 'in-house' scale. Disability was defined at three months after the stroke in NASCET 1991, at six months in ECST 1998 , and at the next routine follow-up assessment in the VACSP 1991 trial.

The modified Rankin Scale is a scale for indicating the degree of disability or dependence in the daily activities of patients who have suffered a stroke or other causes of neurological disability (Farrell 1991). It is a 6-point disability scale with possible scores ranging from 0 to 5 . A score of 0 is no disability, 5 is disability requiring constant care for all needs; 6 is death. For the purposes of the combined analysis in this study, we defined disabling stroke as a stroke that resulted in a Rankin score of 3 or more, or equivalent, at these points of follow-up.

\section{Subgroup analysis and investigation of heterogeneity}

To reduce the risk of chance findings, the collaborators met in 1999 , prior to the pooling of data, to predefine a limited number of subgroups on the basis of potential clinical importance and availability in both trials (Rothwell 2004). These subgroups were derived from the risk factors that were predefined at the beginning of NASCET 1991. The following subgroup analyses were specified:

- men versus women;

- age (less than 65 years old versus 65 to 74 years old versus $75+$ years);

- time from most recent symptomatic ischaemic event to randomisation (less than two weeks, two to four weeks, four to 12 weeks, more than 12 weeks);

- primary ischaemic event in the territory of the stenosed artery during the six months prior to randomisation; this was defined in a hierarchical manner as hemispheric stroke versus hemispheric TIA but no stroke versus retinal event only;

- diabetes versus no diabetes;

- irregular or ulcerated symptomatic carotid plaque versus smooth plaque on the pre-randomisation angiogram; and

- contralateral carotid occlusion versus no occlusion.

To identify any important but unexpected treatment effect modifiers, we identified seven post-hoc subgroup variables on the basis that comparable baseline data were available from the two trials:

- duration of cerebral TIA (one hour or less versus more than one hour);

- previous TIA or stroke (i.e. events prior to the six-month eligibility period, as well as recent events);

- previous myocardial infarction;

- previous angina;

- treated hypertension (defined as that requiring a blood pressure-lowering drug);

- treated hyperlipidaemia (defined as that requiring a dietary change or cholesterol-lowering drug); and

- regular smoking during the previous year.

We first assessed the relationship between each subgroup variable and: 1) the risk of ipsilateral carotid territory ischaemic stroke in participants randomised to medical treatment (medical risk); and 2) any stroke or death that occurred within 30 days after trial surgery (perioperative risk). We determined the five-year cumulative risks of ipsilateral ischaemic stroke in relation to each subgroup variable. We also determined the associations in a Cox proportional hazards model with adjustment for source trial and degree of carotid stenosis.

Determination of the significance of treatment effect modification by subgroup was complicated by the differential changes in event rate with time in the two treatment groups. Nevertheless, we initially performed a Cox proportional hazards model with treatment allocation, a source study term, degree of stenosis, a subgroup by treatment allocation interaction term, and a stenosis by treatment allocation interaction term. We also performed an additional test for trend for the analysis of the effects of age and time from last event to randomisation. To maximise statistical power to detect treatment effect modification by subgroup, we performed these analyses of subgroup by treatment interaction across all degrees of stenosis. We considered it unlikely that the direction of any treatment effect modification by subgroup would differ qualitatively with degree of stenosis. However, we performed 
a further Cox model to test the significance of the three-way interaction between stenosis, subgroup, and treatment allocation.

\section{Sensitivity analysis}

When the decisions for the process undertaken in this systematic review were somewhat arbitrary or unclear, we undertook sensitivity analyses. For example, we performed both fixed-effect and random-effects meta-analyses to evaluate the consistency of the results, or we compared pooled estimates of all studies' results with the results of the studies excluded because of higher risk of bias.

\section{RES ULT S}

\section{Description of studies}

See: Characteristics of included studies, Characteristics of excluded studies, Characteristics of ongoing studies.

\section{Results of the search}

We identified 3884 records from database searching and 120 additional records from other sources in 2019. The searches yielded a total of 2981 records after de-duplication; after title and abstract screening, we retrieved the full texts of 17 records (ACST 2004; Arhuidese 2017; Benavente 2001; Bonati 2018; Columbo 2019; Dakour 2017; Damirel 2018; Huang 2017; Hussain 2018; Knappich 2019; Lichtman 2017; Moore 2019; Muller 2019; Neves 2018; Reiff 2019; Schmid 2017; Song 2017). Finally, after screening the full text, we excluded all 17 articles because they did not meet the inclusion criteria. We did not include any new studies in this update of the review. From the records identified in the previous versions of this review, we identified six randomised trials of endarterectomy plus medical treatment versus medical treatment alone for symptomatic carotid stenosis: we included three (ECST 1998; NASCET 1991; VACSP 1991), excluded two (Fields 1968; Shaw 1984), and identified one ongoing study in Europe (ISRCTN97744893). See Figure 1. It is important to note that the number of studies identified in the searching process was consistently less than in the previous version (Orrapin 2017). This might be due to the application of a new highly sensitive search strategy. In Orrapin 2017 we identified 4122 records from database searching and 155 additional records from other sources. The searches yielded a total of 3783 records after de-duplication; after title and abstract screening, we retrieved the full texts of 57 records. Finally, after screening the full text, we also excluded all 57 articles because they did not meet the inclusion criteria. 
Figure 1. Study flow diagram

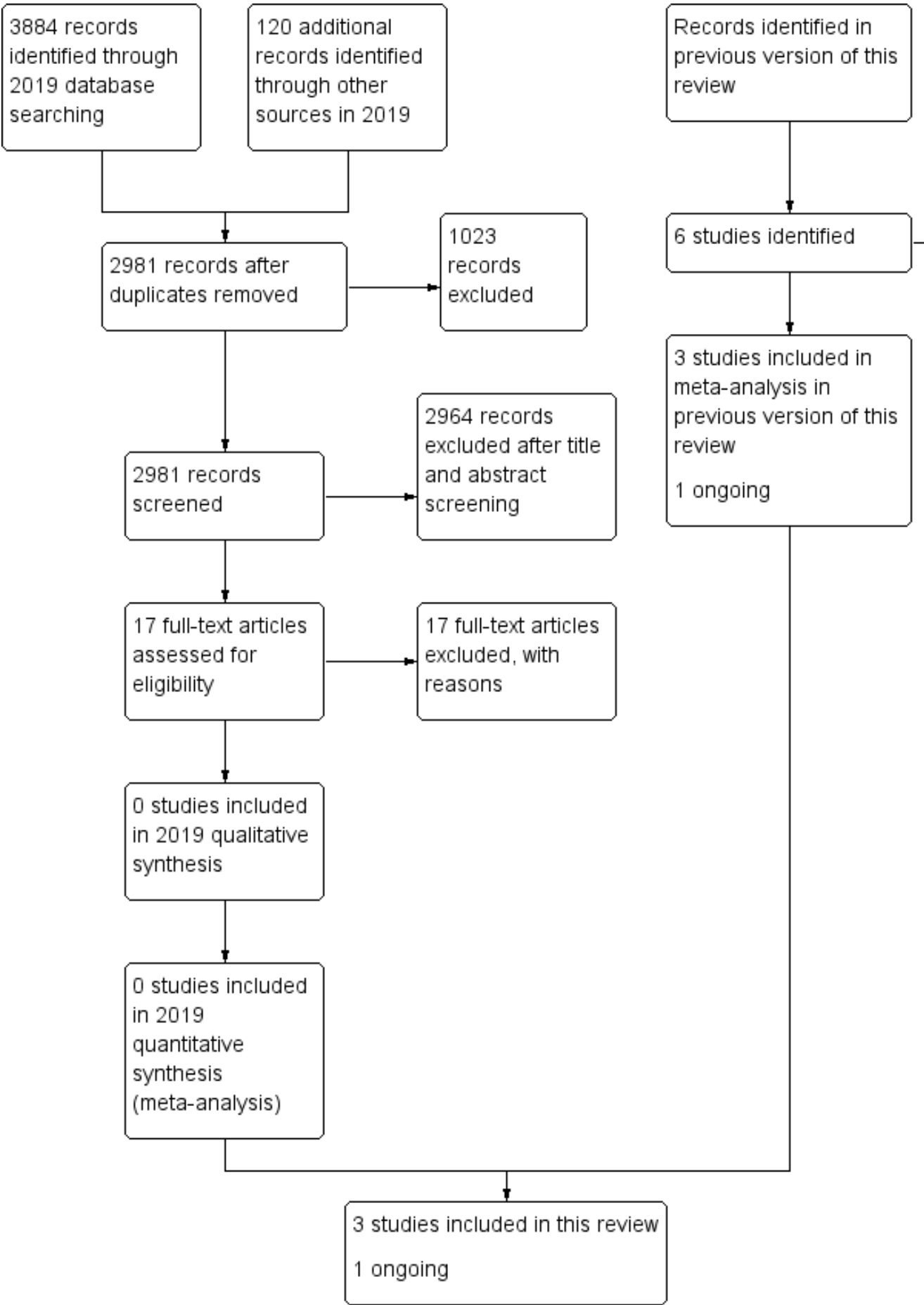

\section{Included studies}

We identified and included three relevant randomised studies (ECST 1998; NASCET 1991; VACSP 1991). Because of remeasurements of the degree of carotid stenosis and certain other baseline clinical characteristics, and changes in the definitions of outcome events, the data reported below differ slightly from the original trial reports. Individual patient data were available for all 6092 participants randomised and included in the final analysis of the three original trials. Of these, one participant in the VACSP
1991 trial had no follow-up data at the time the trial was stopped, nine ECST 1998 participants had an occlusion of the symptomatic carotid artery on the pre-randomisation angiogram, and the degree of stenosis was unknown in one ECST 1998 participant. We did not include these cases in the analyses of the effect of surgery by stenosis group. Thus, we included 6081 (99.8\%) participants in the analyses of the effect of surgery stratified into the prespecified stenosis groups. Mean follow-up was 65 months (standard deviation $(\mathrm{SD})=34$, range $=1$ day to 167 months), giving a total 
of 35,000 patient-years of follow-up, with 1711 stroke outcomes in 1265 participants.

At the outset of NASCET 1991, of those participants in the medical arm, $16 \%$ were on lipid-lowering drugs, $60 \%$ on antihypertensive medication, and $98 \%$ on antithrombotic medication (45\% on aspirin of less than $650 \mathrm{mg} /$ day, $38 \%$ on aspirin of at least 650 $\mathrm{mg} /$ day, 17 on other medication). In ECST 1998, the proportions of medication for at least $50 \%$ of follow-up visits were $79 \%$ for aspirin, $18 \%$ for other antithrombotic drugs, $8 \%$ for anticoagulants, and $8 \%$ for lipid-lowering drugs. In neither trial did medication use differ significantly between the randomised treatment groups.

\section{Comparability of trial designs}

The methods of the three included trials were very similar. Briefly, participants were recruited if they had suffered a recent carotid distribution transient ischaemic attack (TIA), a non-disabling ischaemic stroke, or a retinal infarction, and had a stenosis of the ipsilateral (symptomatic) carotid artery. Prior to randomisation, each trial required that potential participants were seen by a neurologist or a stroke physician to confirm their eligibility, and ensure that the symptomatic carotid artery (and preferably the contralateral carotid artery and intracranial circulation) was imaged by angiography (usually selective catheter angiography). Treatment (immediate carotid endarterectomy plus best medical treatment versus best medical treatment alone) was allocated by central telephone randomisation, stratified by centre. Follow-up was performed at pre-specified intervals by a neurologist or a stroke physician.

ECST 1998 recruited from 100 centres in 14 European countries, NASCET 1991 from 106 centres, mainly in the USA and Canada, but included some centres in Europe, Israel, South Africa, and Australia, and VACSP 1991 recruited from 16 Veterans Affairs medical centres in the USA. Although the trial designs were similar, there were some differences in methods between ECST 1998 and NASCET 1991, and between these trials and the VACSP 1991 trial.

- The VACSP 1991 trial recruited only men; ECST 1998 and NASCET 1991 included both sexes.

- Time from the last cerebrovascular event to randomisation had to be less than four months in the VACSP 1991 trial and in NASCET 1991 (changed to six months after 1991), and less than six months in ECST 1998.

- Inclusion and exclusion in ECST 1998 were based on the 'uncertainty principle', whereas NASCET 1991 and VACSP 1991 had specific criteria. Thus, people with any degree of carotid stenosis could be randomised or treated outside the trial at the discretion of the physician in ECST 1998, whereas the NASCET 1991 and VACSP 1991 trials intended to recruit people only with greater than $30 \%$ and greater than $50 \%$ stenosis, respectively.

- Participants were randomised in a 50:50 ratio (surgery:no surgery) in the NASCET 1991 and VACSP 1991 trials, and in a 60:40 ratio in ECST 1998.

- The recommended dose of aspirin was $1300 \mathrm{mg}$ in NASCET 1991, $325 \mathrm{mg}$ in the VACSP 1991 trial, and was unspecified in ECST 1998.

- Follow-up was at one, three, six, nine, and 12 months, and every four months thereafter in NASCET 1991, at four and 12 months, and annually thereafter in ECST 1998, and at one and three months, and every six months thereafter in the VACSP 1991 trial.

\section{Reassessment of carotid angiograms}

We re-measured the degree of carotid stenosis by the method used in the NASCET 1991 and the VACSP 1991 trials on the 3018 angiograms from ECST 1998 participants in the previous version of this review (Rerkasem 2011). The relationship between the ECST 1998 and NASCET 1991 and VACSP 1991 measurements was linear above $30 \%$ stenosis, and they were highly correlated (correlation coefficienct $=0.94, \mathrm{P}<0.00001$ ), but the ECST 1998 method produced higher values. For example, on average, 50\% and 70\% stenosis by the NASCET 1991 and VACSP 1991 method were equivalent to $65 \%$ and $82 \%$ stenosis, respectively, by the ECST 1998 method. Near-occlusion with post-stenotic narrowing of the internal carotid artery (ICA) presented in 262 participants (125 in ECST 1998 and 137 in NASCET 1991). Inter-observer agreement between the ECST 1998 and NASCET 1991 radiologists in the allocation of the degree of stenosis into the standard categories (less than $30 \%, 30 \%$ to $49 \%, 50 \%$ to $69 \%$, equal to or greater than $70 \%$, near-occlusion) was good (kappa $=0.70,95 \%$ confidence interval $(\mathrm{Cl}) 0.59$ to $0.83, \mathrm{P}<0.0001)$, and there was no systematic bias between the two observers.

\section{Participant characteristics}

Each of the included studies randomised only people who had suffered a recent neurological event in the territory of a stenosed carotid artery. The qualifying events were non-disabling strokes and TIAs, and were variously but sensibly defined. All three studies dealt with an elderly population, predominantly men. All three studies used explicit exclusion criteria, and in addition, ECST 1998 used the 'uncertainty principle'. The uncertainty principle refers to the state of equipoise relating to the intervention. If the patient's physician felt that the patient would clearly benefit, or clearly not benefit, from the surgery, the patient was excluded. Exclusion criteria in common between the studies were: severe coexisting medical disease; possible cardiac causes of emboli; major stroke; angiographic evidence of a second stenotic lesion in the surgically inaccessible portion above the level of the second cervical vertebra (also known as a tandem lesion); and prior ipsilateral carotid endarterectomy.

Comorbidities in the form of ischaemic heart disease, diabetes, hypertension, hypercholesterolaemia, and smoking were well represented among the participants. Participants included in the VACSP 1991 trial were all men and all had at least 50\% symptomatic carotid stenosis. However, they were also less likely to have had a stroke as the presenting event than participants in the other two trials, and they tended to have more vascular risk factors than those in ECST 1998 and NASCET 1991. There were also some differences between ECST 1998 and NASCET 1991. For example, NASCET 1991 included more elderly people, and the median time from last symptoms to randomisation was less than in ECST 1998. However, the trial populations were otherwise broadly comparable.

\section{Excluded studies}

See Characteristics of excluded studies.

Two randomised studies of carotid endarterectomy did not meet inclusion criteria. The first trial was a joint study of extracranial arterial disease. This included not only carotid endarterectomy, but also surgery of the aortic arch branches and vertebral arteries, in symptomatic and 'a few asymptomatic' people. A subgroup analysis of people with unilateral carotid 
disease undergoing carotid endarterectomy included 54\% with vertebrobasilar symptoms (Fields 1968). The second trial reported on carotid endarterectomy done with the unusual adjunct of femoral-carotid bypass and was stopped early because of high postoperative morbidity (Shaw 1984).

\section{Ongoing studies}

There was one ongoing trial: the second European Carotid Surgery trial (ECST-2), which is an international randomised trial investigating the optimal treatment of people with symptomatic or asymptomatic moderate or severe carotid stenosis at low or intermediate risk of future stroke (ISRCTN97744893). The study compares the risks and benefits of treatment by modern optimised medical management alone versus the addition of immediate carotid surgery (or stenting) to optimised medical management. The trial has been recruiting participants since 2012 .

\section{Risk of bias in included studies}

When applying Cochrane's tool for assessing risk of bias, we found that generally, all three included trials had adequate strategies to avoid bias (ECST 1998; NASCET 1991; VACSP 1991), with the exception of VACSP 1991's method of allocation concealment (Higgins 2019; Figure 2; Figure 3). Also, VACSP 1991 was terminated early, before complete recruitment, following the publication of ECST 1998 and NASCET 1991 results. The Cochrane tool assesses the risk of bias of the study on six aspects: sequence generation, allocation concealment, blinding of participants, study personnel, and outcome assessment, incomplete outcome data, selective outcome reporting, and other biases.

Figure 2. 'Risk of bias' graph: review authors' judgements about each 'Risk of bias' item presented as percentages across all included studies

Random sequence generation (selection bias)

Allocation concealment (selection bias)

Blinding of participants and personnel (performance bias): All outcomes

Blinding of outcome assessment (detection bias): All outcomes Incomplete outcome data (attrition bias): All outcomes

Selective reporting (reporting bias)

Other bias

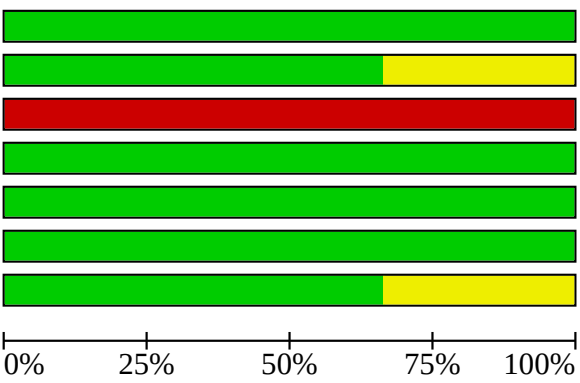


Figure 3. 'Risk of bias' summary: review authors' judgements about each 'Risk of bias' item for each included study

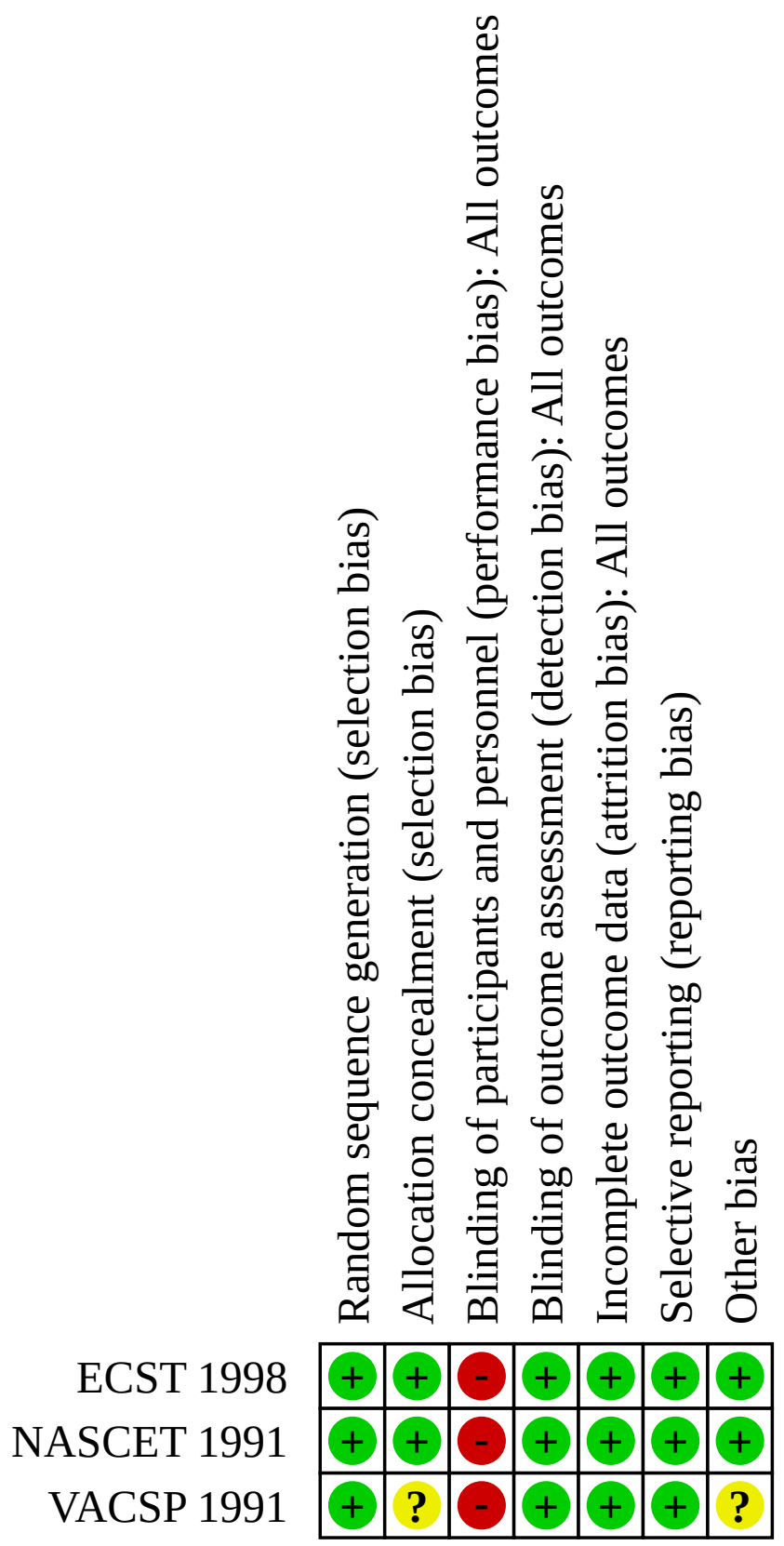

\section{Allocation}

All three included studies were randomised controlled trials with adequate generation of a randomised sequence, and we assessed them to be at low risk of bias. Allocation concealment was adequate in two trials, which we assessed to be at low risk of bias (ECST 1998; NASCET 1991), and unclear in one trial, where it was not clear whether allocation to groups was adequately concealed; we assessed this trial to be at unclear risk of bias (VACSP 1991).

\section{Blinding}

Because of the nature of the intervention, none of the randomised controlled trials (RCT) could be blinded for surgeons or participants. Each study made use of an independent external 
review process for all outcomes, but the clinical data presented for review were derived from the unblinded assessment discussed above, and may, in theory, have been subject to bias. We assessed all three RCTs to be at high risk of bias.

\section{Incomplete outcome data}

Remarkably few participants were lost to follow-up in any of these studies. The designs of the three RCTs are summarised in Characteristics of included studies. Each analysis was conducted on an intention-to-treat principle. After randomisation, a proportion of participants in each arm ultimately received the treatment of the opposite assignment. Such surgical-to-medical crossover was usually because the participant declined surgery after randomisation. Medical-to-surgical crossovers occurred in a small proportion of participants in all studies. In NASCET 1991 and VACSP 1991, but not in ECST 1998, patient follow-up data were censored at the time of medical-to-surgical crossover. We assessed attrition to be at low risk of bias in all three trials.

\section{Selective reporting}

ECST 1998 and NASCET 1991 were both stopped after appropriately pre-specified interim analyses, and VACSP 1991 was also stopped after the results of ECST 1998 and NASCET 1991 were announced, given that it was considered unethical to continue to randomise participants with severe stenosis. This sequence of events was entirely appropriate, and is very unlikely to have introduced any bias into the results. We assessed reporting bias to be at low risk of bias in these three RCTs. The data for the analysis in this review were on all the study outcomes, and all results were included in the analysis. The data were not a subset of the original variables recorded.

\section{Other potential sources of bias}

There was low risk of bias for other potential sources of bias in two RCTs (ECST 1998; NASCET 1991). However, VACSP 1991 was stopped after the results of ECST 1998 and NASCET 1991 were announced. Therefore, the number of participants was low in each arm. We assessed bias to be unclear for this trial (VACSP 1991).

\section{Effects of interventions}

See: Summary of findings 1 Carotid endarterectomy for symptomatic carotid stenosis

\section{Comparison of the results of the individual trials}

Of the participants who were randomised to surgery, 1742/1807 underwent trial surgery in ECST 1998, 1415/1436 in NASCET 1991, and $91 / 91$ in VACSP 1991. The median time from randomisation to trial surgery was two days in the VACSP 1991 trial, three days in NASCET 1991, and 14 days in ECST 1998.

There was no significant difference between the trials in the operative risk of stroke and death $\left(X^{2}=1.1\right.$, degrees of freedom (df) $=2, \mathrm{P}=0.6$ ). There was a non-significant higher operative stroke morbidity in participants with 50\% to $69 \%$ stenosis in the ECST 1998 and VACSP 1991 trials compared to NASCET 1991, but there was no significant difference in operative mortality.

In each of the trials, some of the participants who were randomised to medical treatment had endarterectomy of the symptomatic carotid artery during follow-up. This occurred in a total of 458 participants: $118 / 1211(9.7 \%)$ in ECST 1998, 331/1449 (22.8\%) in NASCET 1991, and 9/98 (9.2\%) in VACSP 1991. The median time (interquartile range: IQR) from randomisation to such surgery was 536 (162 to 975) days in ECST 1998, 555 (217 to 963) days in NASCET 1991 , and 79 (4 to 182) days in VACSP 1991. Surgery was performed most commonly in participants who had severe stenosis at randomisation: $33 / 114$ (28.9\%) near-occlusions; $161 / 506$ (31.8\%) at least $70 \%$ stenosis without near-occlusion; $132 / 721$ (18.3\%) 50\% to $69 \%$ stenosis; $87 / 662$ (13.1\%) $30 \%$ to $49 \%$ stenosis; $44 / 751$ (5.9\%) less than $30 \%$ stenosis. The vast majority of these crossovers occurred after the announcement in 1991, by ECST 1998 and NASCET 1991, that participants with at least $70 \%$ stenosis benefited from surgery; most of the participants who had less than $70 \%$ stenosis at baseline and who were subsequently operated on had progressed to at least $70 \%$ stenosis by the time of surgery.

There were no significant differences between the trials in the risks of the main outcomes in any of the stenosis groups, for either treatment group. There was also no significant heterogeneity between the trials in the effect of the randomised treatment allocation on the relative risks of any of the main outcomes in any of the stenosis groups. The effect of surgery on the relative risks of the main outcomes at five years of follow-up is shown, along with the corresponding absolute risk reductions, by degree of stenosis for ECST 1998 and NASCET 1991 in the Data and analyses section. The results of the VACSP 1991 trial were also included, but were calculated at two years of follow-up, because the trial was stopped early, before follow-up was complete. The apparent lack of benefit from surgery in VACSP 1991, compared with ECST 1998 and NASCET 1991, reflects the low risk of stroke in the medical treatment group at this early stage of follow-up. The trend towards greater harm from surgery in the less than $30 \%$ stenosis group in ECST 1998 versus NASCET 1991, reflected the fact that a higher proportion of participants in this group in ECST 1998 had very mild (less than 10\%) stenosis: 62\% in ECST 1998 and 27\% in NASCET 1991. However, in view of the lack of benefit of surgery in the less than $30 \%$ stenosis group as a whole, we did not do any further subdivision.

\section{Analyses of pooled data}

Since there were no significant differences between the trials, either in the risks of the study outcomes during follow-up in the medical or surgical groups, or in the effects of surgery, we analysed the pooled data. There were no imbalances in baseline characteristics between the surgical and medical groups in the original trials.

Of the 3334 participants who were randomised to surgery, 3248 $(97.5 \%)$ underwent trial surgery. There were $229 / 3248$ strokes or deaths within 30 days of surgery $(7.1 \%, 95 \% \mathrm{Cl} 6.3$ to 8.1$)$, and the risk of death within 30 days of endarterectomy was $1.1 \%$ (35/3248, $95 \% \mathrm{Cl} 0.8$ to 1.5; Table 1). Of the 229 strokes or deaths within 30 days of surgery, there were 214 operative strokes and 15 deaths from a non-stroke cause. The 30-day case fatality for operative strokes was $9.4 \%(20 / 214,95 \% \mathrm{Cl} 5.9$ to 14.4$)$. Table 1 shows the risks of stroke or death within 30 days of trial surgery. Operative risk of stroke and death did not differ between the trials $\left(\mathrm{Chi}^{2}=1.1, \mathrm{df}=\right.$ $2, P=0.6)$. The median time from randomisation to trial surgery was six days. The median time from last symptoms to randomisation in NASCET 1991 was less than in ECST 1998. The median time from the last ischaemic event to randomisation was 36 days in NASCET 1991 and 45 days in ECST 1998. In NASCET 1991, the percentage of 
participants who were randomised within 30 days of event was $42 \%$ for the medical treatment group and $41 \%$ for the surgical treatment group.

\section{Primary outcomes}

\section{Five-year cumulative any stroke or operative death}

There was no significant effect of surgery on the risk of death during follow-up in any of the stenosis groups, in either the individual trials or the pooled data. Surgery tended to be harmful in participants with less than $30 \%$ stenosis (relative risk (RR) $1.25,95 \% \mathrm{Cl} 0.99$ to 1.56) (Analysis 1.1).

In participants with $30 \%$ to $49 \%$ stenosis, the risks of each of the primary outcomes were similar in both treatment groups (RR 0.97 , $95 \% \mathrm{Cl} 0.79$ to 1.19$)$.

In participants with $50 \%$ to $69 \%$ stenosis, surgery was also associated with a higher risk of each of the main outcomes for the first two years of follow-up, but this trend reversed during subsequent follow-up, resulting in significant benefit from surgery for any stroke or operative death (RR $0.77,95 \% \mathrm{Cl} 0.63$ to 0.94 ) (Analysis 1.1).

Five-year cumulative ipsilateral ischaemic stroke, or operative stroke, or operative death.

In participants with $70 \%$ to $99 \%$ stenosis without near-occlusion, there was a highly significant reduction in the surgery group in the risks of each of the main outcomes. Benefit was apparent during the first year of follow-up, reached a maximum by three years, and was still present at eight years ((RR $0.47,95 \% \mathrm{Cl} 0.25$ to 0.88 ) (Analysis 1.2).

The results for participants with near-occlusion were difficult to interpret because of relatively small numbers of patients and outcome events. However, there was no long-term significant benefit from surgery for any of the main outcomes. The difference in the effectiveness of surgery between participants with nearocclusion and participants with $70 \%$ to $99 \%$ stenosis was significant for each outcome: any stroke or operative death (RR 0.95, 95\% Cl 0.59 to $1.53 ; \mathrm{Chi}^{2}$ heterogeneity $=4.1, \mathrm{P}=0.04$ ), and ipsilateral carotid territory ischaemic stroke and operative stroke or death (RR 1.03, $95 \% \mathrm{Cl} 0.57$ to $1.84 ; \mathrm{Chi}^{2}$ heterogeneity $=7.9, \mathrm{P}=0.005$ ) (Analysis 1.1; Analysis 1.2).

Although we presented results in the analyses using the fixed-effect method, where $\mathrm{I}^{2}>0$, we also analysed the data by using the random-effects method; the results were similar.

\section{Secondary outcome}

Five-year cumulative disabling or fatal ipsilateral ischaemic, or operative stroke, and operative death

For the secondary outcomes, we compared benefit versus risk of endarterectomy plus best medical management compared with best medical management alone in terms of disabling or fatal ipsilateral ischaemic or operative stroke and operative death. Benefit was significant in participants with $70 \%$ to $99 \%$ stenosis without near-occlusion (RR $0.40,95 \% \mathrm{Cl} 0.26$ to 0.64 ) (Analysis 1.3). The difference in the effectiveness of surgery between participants with near-occlusion and participants with $70 \%$ to $99 \%$ was significant for disabling or fatal ipsilateral ischaemic or operative stroke and operative death $\left(\mathrm{Chi}^{2}\right.$ heterogeneity $=5.4, \mathrm{P}=$
0.02). The risk of operative stroke or death within 30 days after surgery (Table 1), who underwent trial surgery, was not significantly different between trials (ECST 7.5\%, NASCET 6.5\% and VACSP $7.7 \%)$.

\section{Subgroup analyses}

We did not include the VACSP 1991 trial in the subgroup analyses because the trial was confined to men, and several other subgroup variables were unavailable for analysis. The remaining large trials included $95 \%$ of participants ever randomised to endarterectomy versus medical treatment for symptomatic carotid stenosis (ECST 1998; NASCET 1991). Individual patient data were available for all 5903 participants included in the final analysis of ECST 1998 and NASCET 1991. Of these, nine ECST 1998 participants had an occlusion of the symptomatic carotid artery on the pre-randomisation angiogram, and the degree of stenosis was unknown in one ECST 1998 participant. We excluded these cases from our analyses, leaving 5893 (99.8\%) participants. Mean followup was 66 months (SD $=34$, range $=1$ day to 166 months), giving a total of 33,000 patient-years of follow-up.

\section{Risk of ipsilateral stroke in the medical group}

The risk of ipsilateral stroke in the medical group was significantly related to all of the subgroup variables, apart from contralateral ICA occlusion and smoking (Table 2). Among the predefined subgroups, the risk of ipsilateral ischaemic stroke decreased with time since the last event, increased with age, and was higher in men, in people presenting with hemispheric events than retinal events, in diabetics, and in people with irregular or ulcerated plaques.

\section{Perioperative risk of stroke or death}

Among the 3157 participants who underwent trial surgery, there were 222 operative strokes or deaths $(7.0 \%, 95 \% \mathrm{Cl} 6.2$ to 8.0$)$. Among the predefined subgroups, the perioperative risk of stroke or death was higher in women (Analysis 2.1), and in people with hemispheric events, diabetes, contralateral carotid occlusion, and irregular or ulcerated plaques (Table 3). Among the post-hoc subgroups, perioperative risk was reduced in people with angina, and increased in people with hypertension and with a previous TIA or stroke.

\section{Subgroup-treatment effect modifiers}

As in the original trials, the primary outcome for analyses of the effect of surgery was time to first ipsilateral ischaemic stroke in the territory of the symptomatic carotid artery, and any stroke or death that occurred within 30 days after trial surgery. Table 4 shows the significance of the tests of subgroup treatment effect modification in relative and absolute reductions in the risk of the primary outcome with surgery. Among the predefined subgroups, there was significant heterogeneity of risk reduction by each of the different tests in relation to sex, age, and time since last event. The overall patterns in treatment effect were consistent across the stenosis categories. For example, benefit from carotid endarterectomy in participants with $50 \%$ to $69 \%$ stenosis was significantly less in women $(P=0.04)$, and fell significantly with increasing time since last event $(P=0.009)$. There was no different due to age $(P=0.23)$. The three-way interaction terms in the Cox model did not identify significant relationships between the treatment effect by subgroup interaction and degree of stenosis for any of the subgroups. No significant effects were observed on 
irregular plaque $(P=0.09)$, and primary symptomatic event on treatment effect was greater at higher degrees of stenosis $(P=0.08)$. Benefit tended to be greatest in people with stroke, and to decline progressively in people with cerebral TIA and retinal events, in both the $50 \%$ to $69 \%$ and $70 \%$ to $99 \%$ stenosis groups. Analysis also showed a trend towards greater benefit in people with irregular plaque than a smooth plaque in both stenosis groups. However, these treatment effects by subgroup interactions still failed to reach significance when the analysis was restricted to people with $50 \%$ to $99 \%$ stenosis: $\mathrm{P}=0.06$ for irregular plaque, and $\mathrm{P}=0.1$ for primary symptomatic events.

No subgroup-treatment effect interaction term was significant at the $\mathrm{P}<0.01$ level set for the post-hoc subgroups.

To assess the consistency of the effects of sex, age, and time since last event on the benefit of carotid endarterectomy, we analysed ECST 1998 and NASCET 1991 separately for people with 50\% to 99\% stenosis. This allowed us to focus on the participants who appeared to gain benefit from carotid endarterectomy (based on the previous report). Both trials showed the same patterns. For participants with $50 \%$ to $99 \%$ stenosis, the estimates of the number of people who needed to undergo surgery to prevent one ipsilateral stroke in five years from the pooled data were nine for men versus 36 for women, five for age 75 years or older versus 18 for age less than 65 years, and five for people randomised within two weeks versus 125 for people randomised more than 12 weeks ( 10 and 18 for people randomised two to four weeks and four to 12 weeks respectively).

\section{DISCUSSION}

\section{Summary of main results}

\section{Benefit of surgery in relation to degree of carotid stenosis}

Carotid surgery is beneficial for people with a significant degree of carotid artery stenosis. Carotid endarterectomy reduced fiveyear cumulative any stroke or operative death (RR 0.77, 95\% $\mathrm{Cl} 0.63$ to 0.94 and RR $0.53,95 \% \mathrm{Cl} 0.42$ to 0.67 of $50 \%$ to $69 \%$ stenosis and $70 \%$ to $99 \%$ stenosis, respectively) (Analysis 1.1). Carotid surgery decreased five-year cumulative ilpsilateral ischaemic stroke and any operative stroke or death (RR 0.47, 95\% $\mathrm{Cl} 0.25$ to 0.88 (Analysis 1.2). It also reduced five-year cumulative disabling or fatal ipsilateral ischaemic or operative stroke and death (RR $0.40,95 \% \mathrm{Cl} 0.26$ to 0.64 ) (Analysis 1.3) in severe degree of carotid artery stenosis (70\% to $99 \%$ stenosis). With the exception of near-occlusions, carotid surgery is beneficial for reducing fiveyear cumulative any stroke or operative death and was shown to be 50\% (by the measurement used in the NASCET 1991 and VACSP 1991 trials: equivalent to about $65 \%$ stenosis by the method used in ECST 1998). Benefit of surgery in people with $50 \%$ to $69 \%$ stenosis became more modest with longer duration of follow-up in reducing five-year cumulative any stroke or operative death (Analysis 1.1). Lack of benefit of surgery in patients with moderate stenosis in the original ECST 1998 report is not inconsistent with this, but reflects the differences between the analyses in the measurement of stenosis and the definition of outcome events. The re-analysis of individual patient data showed that the effects of surgery in ECST 1998 and NASCET 1991 in people with 50\% to 69\% stenosis were demonstrated by the reduction of five-year cumulative any stroke or operative death, which were consistent.
It is possible that the intention-to-treat analysis may have underestimated the benefit of endarterectomy for reducing the five-year cumulative reduction of any stroke, ipsilateral ischaemic stroke, disabling or fatal ipsilateral ischaemic stroke and death in near-occlusions because of the relatively high rate of endarterectomy during follow-up in the medical treatment group in NASCET 1991. However, the rate of endarterectomy was the same in the participants with $70 \%$ to $99 \%$ stenosis without near occlusion, and yet there was considerable benefit of surgery to reduce fiveyear cumulative any stroke, ipsilateral ischaemic stroke, disabling or fatal ipsilateral ischaemic stroke and death by intention-totreat analysis in this group. Moreover, there was no benefit from surgery to reduce the five-year cumulative any stroke, ipsilateral ischaemic stroke, disabling or fatal ipsilateral ischaemic stroke and death in the near-occlusion group in ECST 1998, where the rate of endarterectomy in the medical group was lower than in NASCET 1991. The confidence intervals around the estimates of treatment effect in the near-occlusions were wide $(95 \% \mathrm{Cl} 0.59$ to $1.53,95 \% \mathrm{Cl}$ 0.57 to 1.84 and $95 \% \mathrm{Cl} 0.51$ to 3.27 for the three main outcomes Analysis 1.1, Analysis 1.2, and Analysis 1.3, respectively), but the difference in the effect of surgery between this group and people with $70 \%$ to $99 \%$ stenosis without near occlusion was beneficial to reduce the five-year cumulative any stroke, ipsilateral ischaemic stroke, disabling or fatal ipsilateral ischaemic stroke and death (RR $0.53,95 \% \mathrm{Cl} 0.42$ to 0.67 , RR $0.47,95 \% \mathrm{Cl} 0.25$ to 0.88 and RR $0.40,95 \% \mathrm{Cl} 0.26$ to 0.64 for the three main outcomes Analysis 1.1, Analysis 1.2, and Analysis 1.3, respectively). Some people may still wish to undergo surgery, particularly if they experience recurrent transient ischaemic attacks (TIAs), but they should be informed that the benefit from endarterectomy in preventing a stroke is likely to be modest in the short-term and unknown in the long-term.

\section{Overall completeness and applicability of evidence}

\section{Operative risk}

The $7 \%$ operative risk of stroke and death within 30 days of endarterectomy included any stroke (ocular or cerebral) with symptoms lasting longer than 24 hours. It is consistent with previous surgical case series in which patients were also assessed postoperatively by a neurologist. However, recent national audit reports from Germany and the UK have published 30-day stroke and death risks of less than $4 \%$, indicating that the risk of postoperative stroke and death have significantly reduced over the last two decades (ESVS 2018). The benefits of surgery outlined above will only be obtained in routine clinical practice if the operative risk is low (Table 1). Since it is likely that minor strokes are regularly missed in routine clinical practice outside strictly organised clinical trials, an audit of operative risk should be performed by an independent neurologist or stroke physician (Bond 2004). The 30day case fatality for operative stroke in the pooled analysis of the trials was $9.6 \%$ (95\% confidence interval (CI) 5.9 to 14.4 ), and the ratio of non-fatal to fatal operative strokes was 10:1. The possibility that non-fatal strokes have been missed should be considered in any surgical audit in which the ratio of non-fatal to fatal outcomes is lower.

\section{Subgroup analyses}

The pooled analysis of ECST 1998 and NASCET 1991 found three significant and clinically important subgroup treatment effect modifiers among the predefined subgroup variables. Benefit from surgery was greater in men than in women, and in the elderly, 
and benefit decreased with time since the last symptoms. These observations were consistent across the $50 \%$ to $69 \%$ and $70 \%$ to $99 \%$ stenosis groups, and across the two trials. These subgroup observations were sufficiently robust to be used to guide the use of carotid endarterectomy in routine clinical practice.

In most trials of treatments for vascular disease, such as trials of blood pressure-lowering or lipid-lowering therapies, the effects of risk factors on the main outcome events are qualitatively similar in the treatment and control groups. The analysis of subgroup effects in the case of carotid endarterectomy is more complicated because the overall effect of surgery is determined by the balance of two different outcomes (ipsilateral carotid territory ischaemic stroke with medical treatment versus the perioperative risk of stroke or death within 30 days of carotid endarterectomy), which have very different mechanisms. Therefore, particular risk factors might have qualitatively different effects on each outcome. This was the case in our analysis for sex, increasing age, and shorter time from last event to randomisation.

Women had a lower risk of ipsilateral ischaemic stroke with medical treatment and a higher operative risk compared with men. These same patterns have also been shown in the two large trials of carotid endarterectomy for asymptomatic stenosis (ACAS 1995; ACST 2004). Carotid endarterectomy is very clearly beneficial in women with $70 \%$ to $99 \%$ symptomatic stenosis, but not in women with $50 \%$ to $69 \%$ stenosis. Whether surgery is still indicated in individual women will depend on the balance of their other risk factors.

It could be argued that the increased benefit from surgery in people over 75 years old might not be generalisable to routine clinical practice, because trial participants generally have a good prognosis, and elderly people might have a greater operative risk in clinical practice (Bond 2005). However, there is no justification for withholding carotid endarterectomy in people over 75 years old who are deemed to be medically fit to undergo surgery. The subgroup analyses of ECST 1998 and NASCET 1991 indicated that benefit was likely to be greatest in this group, because of their high risk of stroke with medical treatment, although it is important to note that the trials included very few participants over the age of 80 years.

The urgency with which carotid endarterectomy should be performed has been much debated. The risk of stroke with medical treatment after a TIA or minor stroke falls rapidly over the subsequent year, possibly because of the 'healing' of the unstable atheromatous plaque or an increase in collateral blood flow to the symptomatic hemisphere, but there have been no reliable data on the extent to which the effectiveness of carotid endarterectomy also falls with time. There has been concern that the operative risk may be increased if surgery is performed early, particularly in people with major cerebral infarction or stroke-inevolution (Rerkasem 2009). For neurologically stable people, such as those enrolled in the trials, benefit from carotid endarterectomy was greatest in those randomised within two weeks of their last event, and fell rapidly with increasing delay. Following the publication of international guidelines (AHA 2011; ESVS 2018), time to intervention has improved markedly over the last decade, with the median time from index event to intervention in the UK currently standing at 12 days (National Vascular Registry 2019). However, many patients continue to undergo carotid endarterectomy for symptomatic stenosis more than two weeks after their presenting event, and some are operated on more than 12 weeks after the event, when benefit is considerably reduced in people with $70 \%$ to $99 \%$ stenosis, and absent in those with $50 \%$ to $69 \%$ stenosis (Rothwell 2004).

\section{Quality of the evidence}

Generally, the three included trials had adequate strategies to avoid bias in their study, except VACSP 1991, which did not provide information on allocation concealment. Analysis of individual patient data has advantages over meta-analysis of overall trial results, and was essential for the endarterectomy trials. Differences between the trials in the method of measurement of carotid stenosis and in the definition of outcome events made it impossible to combine tabular results satisfactorily. By re-analysing the individual patient data, and reassessing the carotid angiograms, we showed that the results of ECST 1998 and NASCET 1991 were consistent, removing the uncertainty that was generated by the apparent disparities between the originally reported results of the trials. In summary, the quality of the evidence for near occlusion and less than $30 \%$ of carotid stenosis is high. The quality of the evidence for $50 \%$ to $99 \%$ of carotid stenosis is moderate for any stroke or operative death, as well as for ipsilateral ischaemic stroke and any operative stroke or death outcome.

\section{Potential biases in the review process}

The dangers of subgroup analysis, particularly the selective reporting of multiple post-hoc analyses, are well documented. However, we believe that the subgroup analyses of the pooled data from ECST 1998 and NASCET 1991 were reliable. We chose the predefined analyses prior to pooling the trial data, and we reported all of the analyses that we performed. Significance testing was based on the overall interaction of the subgroup variable with the treatment effect, rather than the significance of the treatment effect within each subgroup category. Statistical tests of subgroup-treatment effect interaction terms were conservative, and a $P$ value $<0.1$ is generally regarded as significant. However, to reduce the risk of chance findings, $\mathrm{P}<0.05$ was required for predefined subgroups and $\mathrm{P}<0.01$ for post-hoc subgroups. It was also fortunate to have two major trials with very similar methods, and therefore, to be able to assess the consistency of observations in two completely independent studies. Indeed, the consistency in the subgroup effects between the trials was more convincing than the significance of the overall effects.

\section{Agreements and disagreements with other studies or reviews}

In 2012, a systematic review was carried out to compare long-term rates of stroke or death for carotid endarterectomy plus medical treatment versus medical therapy alone, in people suffering from carotid artery stenosis (Guay 2012). This systematic review included evidence up to August 2011. For symptomatic carotid stenosis, ECST 1998 and NASCET 1991 were included. The review reported that for people with symptomatic carotid stenosis (50\% to $99 \%$ ), there was a significantly lower risk of stroke or death among people who had carotid endarterectomy plus medical treatment compared with people who received medical treatment alone from two to five years of follow-up (relative risk $0.69,95 \% \mathrm{Cl} 0.59$ to 0.81 ; NASCET 1991). The number needed to treat for a beneficial outcome was 11 patients $(95 \% \mathrm{Cl} 8$ to 17$)$. For people without stenosis (less than $50 \%$ stenosis), there was no significant differences in the risk of stroke 
or death between the two groups. These results are similar to the findings in our review.

In 2015, a systematic review was performed of all available guidelines for the treatment of carotid artery stenosis, published in any language between 1 January 2008 and 28 January 2015. There were 33 guidelines for symptomatic carotid stenosis. Thirty-one of these guidelines (94\%) recommended that carotid endarterectomy should be performed in people with average risk symptomatic carotid stenosis of $50 \%$ to $99 \%$ (Abbott 2015). The remaining two guidelines did not recommend carotid endarterectomy for all symptomatic carotid stenosis, because of a limited number of surgeons with high volume experience in carotid endarterectomy. To some extent, they also preferred carotid artery stenting to carotid endarterectomy (Bladin 2011; Liu 2012).

\section{AUTHORS' CONCLUSIONS}

\section{Implications for practice}

Even though other factors also determine the effect of endarterectomy, the degree of carotid stenosis is the single most important factor. This systematic review and meta-analysis of the original trials with methods of measurement of stenosis and standardised definitions of primary and secondary outcomes indicated highly consistent results. The degree of stenosis above which surgery is beneficial is $50 \%$, although benefit in patients with $70 \%$ stenosis or more is markedly more than in those with $50 \%$ to $69 \%$ stenosis. Patients with carotid near-occlusion are different from patients with $70 \%$ or greater stenosis without near occlusion, and have a lower risk of stroke on medical treatment. The evidence indicates that benefit from carotid endarterectomy in patients with carotid near-occlusion is marginal.

The trials included in this review were performed in the 1980s and early 1990s, prior to the widespread use of statins and other recent developments in medical therapy (Marquardt 2010). The risk of stroke for recently symptomatic patients with the best medical therapy may well have reduced over the last two decades since the trials, and so it is possible that the benefits of endarterectomy may be less than estimated. However, the risk of postoperative stroke and death have also significantly reduced over time; currently less than $3 \%$ in most countries (ESVS 2018), and $2.0 \%$ in the latest UK
National Vascular Registry Report 2019 (National Vascular Registry 2019). Therefore, it is likely that early, appropriate intervention will continue to be highly beneficial for symptomatic patients with highgrade ipsilateral carotid artery stenosis. The ongoing ECST-2 trial is addressing this question (ISRCTN97744893).

\section{Implications for research}

Medical therapy for stroke prevention has improved since ECST 1998 and NASCET 1991 reported their findings, with more widespread use of statins, more effective antiplatelet medication, and a more active use of antihypertensive medication. Lower optimum targets have been determined for risk factor control e.g. blood pressure. However, the risk of postoperative stroke and death following carotid endarterectomy have also significantly reduced over time. Therefore, it is possible that urgent carotid endarterectomy in patients with high-grade carotid stenosis, treated by modern optimised medical therapy will continue to be highly beneficial. The ongoing ECST-2 trial will reevaluate the efficacy of carotid intervention in the current era (ISRCTN97744893). There remains scope for further research to define whether carotid endarterectomy is safe in the hyperacute setting ( $<48$ hours after index symptoms), as risk of stroke with medical therapy is greatest in the first few days after the index event (ESVS 2018). With recent advances in the use of systemic and catheter-directed thrombolysis for acute stroke, there is also scope for further research to investigate the optimal timing of carotid endarterectomy in patients with ipsilateral high-grade carotid stenosis, identified following recent thrombolysis. Finally, some people with $<50 \%$ carotid artery stenosis who are recently symptomatic, continue to suffer recurrent symptoms, despite the best medical therapy. Further research is required to confirm if these people can be identified, and whether they would benefit from carotid endarterectomy.

\section{ACKNOWLEDGEM NTS}

We thank Professor PM Rothwell, Dr CS Cinà, Dr CM Clase, and Dr $\mathrm{R}$ Brian Hayes for their contribution to previous versions of this review; Hazel Fraser and Joshua David Cheyne for providing us with references to relevant trials from the Cochrane Stroke Group Trials Register; and Dr Eliasziw and Professor Warlow for their contribution to the subgroup analyses. 


\section{R E F E R E N C E S}

\section{References to studies included in this review}

\section{ECST 1998 \{published data only\}}

Boiten J, Rothwell PM, Slattery J, Warlow CP. Ischaemic lacunar stroke in the European Carotid Surgery Trial. Risk factors, distribution of carotid stenosis, effect of surgery and type of recurrent stroke. Cerebrovascular Diseases 1996;6:281-7.

European Carotid Surgery Trialists' Collaborative Group (ECST). Endarterectomy for moderate symptomatic carotid stenosis: interim results from the MRC European Carotid Surgery Trial. Lancet 1996;347:1591-3.

European Carotid Surgery Trialists' Collaborative Group (ECST). MRC European Carotid Surgery Trial: interim results for symptomatic patients with severe $(70-99 \%)$ or with mild $(0-$ 29\%) carotid stenosis. Lancet 1991;337:1235-43.

* European Carotid Surgery Trialists' Collaborative Group. Randomised trial of endarterectomy for recently symptomatic carotid stenosis: final results of the MRC European Carotid Surgery Trial (ECST). Lancet 1998;351:1379-87.

Warlow CP. Symptomatic patients: the European Carotid Surgery Trial (ECST). Journal des Maladies Vasculaires 1993;18:198-201.

\section{NASCET 1991 \{published data only\}}

Barnett HJM, Taylor DW, Eliasziw M, Fox AJ, Ferguson GG, Haynes BR, et al. Benefit of carotid endarterectomy in patients with symptomatic moderate or severe stenosis. New England Journal of Medicine 1999;339(20):1415-25.

Barnett HJM. North American Symptomatic Carotid Endarterectomy Trial. Methods, patient characteristics, and progress. Stroke 1991;22:711-20.

Barnett HJM. Status report on the North American Symptomatic Carotid Surgery Trial. Journal des Maladies Vasculaires 1993;18:202-8.

Barnett HJM. Symptomatic carotid endarterectomy trials. Stroke 1990;21(11):III-2-5.

Barnett HJM. The randomized trials of endarterectomy in symptomatic carotid stenosis. Platelets 1993;4 Suppl 1:17-8.

Eliasziw M, Streifler JY, Fox AJ, Hachinski VC, Ferguson GG, Barnett HJ. Significance of plaque ulceration in symptomatic patients with high-grade carotid stenosis. North American Symptomatic Carotid Endarterectomy Trial. Stroke 1994;25:304-8.

Gasecki AP, Eliasziw M, Ferguson GG, Clagett GP, Hachinski VC, Barnett HJM. Early endarterectomy for severe carotid artery stenosis after a nondisabling stroke: results from the North American Symptomatic Carotid Endarterectomy Trial. Journal of Vascular Surgery 1994;20:288-95.

Gasecki AP, Eliasziw M, Ferguson GG, Hachinski V, Barnett HJ. Long-term prognosis and effect of endarterectomy in patients with symptomatic severe carotid stenosis and contralateral carotid stenosis or occlusion: results from NASCET. North American Symptomatic Carotid Endarterectomy Trial (NASCET) group. Journal of Neurosurgery 1995;83:778-82.

Haynes RB, Taylor DW, Sackett DL, Thorpe K, Ferguson GG, Barnett HJM. Prevention of functional impairment by endarterectomy for symptomatic high-grade carotid stenosis. JAMA 1994;271:1256-9.

Morgenstern LB, Fox AJ, Sharpe BL, Eliasziw M, Barnett HJ, Grotta JC. The risks and benefits of carotid endarterectomy in patients with near occlusion of the carotid artery. Neurology 1997;48:911-5.

NASCET Investigators. Clinical alert: benefit of carotid endarterectomy for patients with high-grade stenosis of the internal carotid artery. National Institute of Neurological Disorders and Stroke, Stroke and Trauma Division. North American Symptomatic Carotid Endarterectomy Trial (NASCET) Investigators. Stroke 1991;22:816-7.

NASCET Study Group. Carotid endarterectomy: three critical evaluations. North American Symptomatic Carotid Endarterectomy Study Group. Stroke 1987;18:987-9.

* North American Symptomatic Carotid Endarterectomy Trial Collaborators (NASCET). Beneficial effect of carotid endarterectomy in symptomatic patients with highgrade carotid stenosis. New England Journal of Medicine 1991;325:445-53.

Paddock-Eliasziw LM, Eliasziw M, Barr WK, Barnett HJM. Longterm prognosis and the effect of carotid endarterectomy in patients with recurrent ipsilateral ischemic events. Neurology 1996;47:1158-62.

Rothwell P. Can overall results of clinical trials be applied to all patients? Lancet 1995;345:1616-9.

Streifler JY, Eliasziw M, Benavente OR, Harbison JW, Hachinski VC, Barnett HJ, et al. The risk of stroke in patients with first-ever retinal vs. hemispheric transient ischemic attacks and high-grade carotid stenosis. Archives of Neurology 1995;52:246-9.

\section{VACSP 1991 \{published data only\}}

* Mayberg MR, Wilson SE, Yatsu F, Weiss DG, Messina L, Hershey LA, et al. Carotid endarterectomy and prevention of cerebral ischemia in symptomatic carotid stenosis. JAMA 1991;266:3289-94.

Wilson SE, Mayberg MR, Yatsu F, Weiss DG, the Veterans Affairs Trialists. Crescendo transient ischemic attacks: a surgical imperative. Journal of Vascular Surgery 1993;17:249-56.

\section{References to studies excluded from this review}

ACST 2004 \{published data only\}

Halliday A, Mansfield A, Marro J, Peto C, Peto R, Potter J, MRC Asymptomatic Carotid Surgery Trial (ACST) Collaborative Group. Prevention of disabling and fatal strokes by 
successful carotid endarterectomy in patients without recent neurological symptoms: randomised controlled trial. Lancet 2004;363:1491-502.

\section{Arhuidese 2017 \{published data only\}}

Arhuidese I, Obeid T, Nejim B, Locham S, Hicks CW, Malas MB. Stenting versus endarterectomy after prior ipsilateral carotid endarterectomy. Journal of Vascular Surgery 2017;65(1):1-11.

\section{Benavente 2001 \{published data only\}}

Benavente O, Eliasziw M, Streifler JY, Fox AJ, Barnett HJM, Meldrum $\mathrm{H}$, the NASCET trial. Prognosis after transient monocular blindness associated with carotid artery stenosis. New England Journal of Medicine 2001;345:1084-90.

\section{Bonati 2018 \{published data only\}}

Bonati LH, Gregson J, Dobson J, McCabe DJH, Nederkoorn PJ, van der Worp HB, et al. Restenosis and risk of stroke after stenting or endarterectomy for symptomatic carotid stenosis in the International Carotid Stenting Study (ICSS): secondary analysis of a randomised trial. Lancet Neurology 2018;17(7):587-96.

\section{Columbo 2019 \{published data only\}}

Columbo JA, Martinez-Camblor P, MacKenzie TA, Kang R, Trooboff SW, Goodney PP, et al. A comparative analysis of long-term mortality after carotid endarterectomy and carotid stenting. Journal of Vascular Surgery 2019;69(1):104-9.

\section{Dakour 2017 \{published data only\}}

Dakour AH, Locham S, Nejim B, Malas MB. Comparison of 30day readmission rates and risk factors between carotid artery stenting and endarterectomy. Journal of Vascular Surgery 2017;66(5):1432-44.

\section{Damirel 2018 \{published data only\}}

Demirel S, Böckler D, Storck M. Comparison of long-term results of carotid endarterectomy for asymptomatic carotid artery stenosis. Gefasschirurgie 2018;23 Suppl 1:1-7.

\section{Fields 1968 \{published data only\}}

Bauer RB, Meyer JS, Fields WS, Remington R, Macdonald MC, Callen P. Joint study of extracranial arterial occlusion. 3 Progress report of controlled study of long-term survival in patients with and without operation. JAMA 1969;208:509-18.

Blaisdell WF, Clauss RH, Galbraith JG, Imparato AM, Wylie EJ. Joint study of extracranial arterial occlusion. IV - A review of surgical considerations. JAMA 1969;209:1889-95.

Corcoran PJ, Hass WK. Random controls in the clinical study of ischemic strokes. Statistical analysis of 100 patients with angiography. American Journal of Physical Medicine 1968;47:240-6.

Fields WS, Lemak NA. Joint study of extracranial arterial occlusion. X - Internal carotid artery occlusion. JAMA 1976;235:2734-8.

Fields WS, Maslenikov V, Meyer JS, Hass WK, Remington R, Macdonald MC. Joint study of extracranial arterial occlusion. V - Progress report of prognosis following surgery or nonsurgical treatment for transient cerebral ischemic attacks and cervical carotid artery lesions. JAMA 1970;211:1993-2003.

* Fields WS, North RR, Hass WK, Galbraith JG, Wylie EJ, Ratinov G, et al. Joint study of extracranial arterial occlusion as a cause of stroke. 1 - Organization of study and survey of patient population. JAMA 1968;203:153-8.

Hass WK, Fields WS, North RR, Kricheff II, Chase NE, Bauer RB. Joint study of extracranial arterial occlusion. 2 - Arteriography, techniques, sites, and complications. JAMA 1968;203:159-66.

\section{Huang 2017 \{published data only\}}

Huang Y, Gloviczki P, Duncan AA, Kalra M, Oderich GS, DeMartino RR, et al. Outcomes after early and delayed carotid endarterectomy in patients with symptomatic carotid artery stenosis. Journal of Vascular Surgery 2018;67(4):1110-9.

\section{Hussain 2018 \{published data only\}}

Hussain MA, Mamdani M, Tu JV, Aljabri B, Bhatt DL, Verma S, et al. Long-term outcomes of carotid endarterectomy versus stenting in a multicenter population-based Canadian study. Annals of Surgery 2018;268(2):364-73.

\section{Knappich 2019 \{published data only\}}

Knappich C, Kuehnl A, Haller B, Salvermoser M, Algra A, Becquemin JP, et al. Associations of perioperative variables with the 30-day risk of stroke or death in carotid endarterectomy for symptomatic carotid stenosis. Stroke 2019;50(12):3439-48.

\section{Lichtman 2017 \{published data only\}}

Lichtman JH, Jones MR, Leifheit EC, Sheffet AJ, Howard G, Lal BK, et al. Carotid endarterectomy and carotid artery stenting in the US Medicare population, 1999-2014. JAMA 2017;318(11):1035-46.

\section{Moore 2019 \{published data only\}}

Moore WS, Voeks JH, Roubin GS, Clark WM, Howard VJ, Jones MR, et al. Duration of asymptomatic status and outcomes following carotid endarterectomy and carotid artery stenting in the Carotid Revascularization Endarterectomy vs Stenting Trial. Journal of Vascular Surgery 2019;69(6):1797-1800.

\section{Muller 2019 \{published data only\}}

Müller MD, Jongen LM, Altinbas A, Blackham KA, Nederkoorn PJ, Macdonald $S$, et al. Silent intracerebral hemorrhage in patients randomized to stenting or endarterectomy for symptomatic carotid stenosis. J Stroke. 2019;21(1):116-9.

\section{Neves 2018 \{published data only\}}

Neves CRB, Casella IB, da Silva ES, Puech-Leão P. Medical therapy for asymptomatic patients and stent placement for symptomatic patients presenting with carotid artery near-occlusion with full collapse. Journal of Vascular and Interventional Radiology 2018;29(7):998-1005.

\section{Reiff 2019 \{published data only\}}

Reiff T, Eckstein HH, Mansmann U, Jansen O, Fraedrich G, Mudra $\mathrm{H}$, et al. Angioplasty in asymptomatic carotid artery stenosis vs. endarterectomy compared to best medical 
treatment: one-year interim results of SPACE-2. International Journal of Stroke 2019. [DOI: 10.1177/1747493019833017]

\section{Schmid 2017 \{published data only\}}

Schmid S, Tsantilas P, Knappich C, Kallmayer M, König T, Breitkreuz T, et al. Risk of inhospital stroke or death is associated with age but not sex in patients treated with carotid endarterectomy for asymptomatic or symptomatic stenosis in routine practice: secondary data analysis of the Nationwide German Statutory Quality Assurance Database from 2009 to 2014. Journal of the American Heart Association 2017;6(3):e004764.

\section{Shaw 1984 \{published data only\}}

Shaw DA, Venables GS, Cartlidge NE, Bates D, Dickinson PH. Carotid endarterectomy in patients with transient cerebral ischemia. Journal of the Neurological Sciences 1984;64:45-53.

\section{Song 2017 \{published data only\}}

Song R, Sun X, Qu B, Song L, Wang Z. Comparative efficacy and safety of carotid endarterectomy and carotid angioplasty stenting in the treatment of asymptomatic carotid artery stenosis. International Journal of Clinical and Experimental Medicine 2017;10(7):10773-81.

\section{References to ongoing studies}

\section{ISRCTN97744893 \{unpublished data only\}}

Featherstone RL, Kennedy F, Brown MM. The 2nd European Carotid Surgery Trial (ECST-2). 21st European Stroke Conference. 22-25 May 2012; Lisbon, Portugal. s489637516.websitehome.co.uk/ECST2/protocolsummary.html (accessed 18 January 2017).

* ISRCTN97744893. European Carotid Surgery Trial 2. www.isrctn.com/ISRCTN97744893 (first received 7 May 2012).

\section{Additional references}

\section{Abbott 2015 \\ Abbott AL, Paraskevas KI, Kakkos SK, Golledge J, Eckstein HH, Diaz-Sandoval LJ, et al. Systematic review of guidelines for the management of asymptomatic and symptomatic carotid stenosis. Stroke 2015;46(11):3288-301. [DOI: 10.1161/ STROKEAHA.115.003390]}

\section{ACAS 1995}

Executive Committee for the Asymptomatic Carotid Atherosclerosis Study. Endarterectomy for asymptomatic carotid artery stenosis. JAMA 1995;273:1421-8.

\section{AHA 2011}

Brott TG, Halperin JL, Abbara S, Bacharach JM, Barr JD, Bush RL, American College of Cardiology Foundation/ American Heart Association Task Force on Practice Guidelines, American Stroke Assocation, American Association of Neuroscience Nurses, American Association of Neurological Surgeons, American College of Radiology, American Society of Neuroradiology, Congress of Neurolgocial Surgeons, Society of Atherosclerosis Imaging and Prevention, Society for Cardiovascular Angiography and Interventions, Society of Interventional Radiology, Society of NeuroInterventional Surgery, Society for Vascular Medicine, Society for Vascular Surgery, American Academy of Neurology and Society of Cardiovascular Computed Tomography. 2011ASA/ACCF/ AHA/AANN/AANS/ACR/ASNR/CNS/SAIP/SCAI/SIR/SNIS/ SVM/SVS guideline on the management of patients with extracranial carotid and vertebral artery disease. Stroke 2011;42(8):e464-540.

\section{Alamowitch 2001}

Alamowitch S, Eliasziw M, Algra A, Meldrum H, Barnett HJM, the NASCET trial. Risk, causes and prevention of ischaemic stroke in elderly patients with symptomatic internal carotid artery stenosis. Lancet 2001;357:1154-60.

\section{Bamford 1990}

Bamford J, Sandercock P, Dennis M, Burn J, Warlow C. A prospective study for acute cerebrovascular disease in the community: the Oxfordshire Community Stroke Project 1981-1986. Incidence, case fatality and overall outcome at one year of cerebral infarction, primary intra-cerebral hemorrhage and subarachnoid hemorrhage. Journal of Neurology, Neurosurgery, and Psychiatry 1990;53:16-22.

\section{Bladin 2011}

Bladin C, Chambers B, Crimmins D, Donnan G, Frayne J, Levi C, Carotid Stenting Guidelines Committee: an Intercollegiate Committee of the RACP (ANZAN, CSANZ), RACS (ANZSVS) and RANZCR. Guidelines for patient selection and performance of carotid artery stenting. Internal Medicine Journal 2011;41:344-7.

\section{Bond 2004}

Bond R, Rerkasem K, Shearman CP, Rothwell PM. Time trends in the published risks of stroke and death due to endarterectomy for symptomatic carotid stenosis. Cerebrovascular Diseases 2004;18:37-46.

\section{Bond 2005}

Bond R, Rerkasem K, Cuffe R, Rothwell PM. A systematic review of the associations between age and sex and the operative risks of carotid endarterectomy. Cerebrovascular Diseases 2005;20:69-77.

\section{Bonita 1992}

Bonita R. Epidemiology of stroke. Lancet 1992;339:342-4.

\section{Deeks 2011}

Deeks JJ, Higgins JPT, Altman DG, editor(s). Chapter 9: Analysing data and undertaking meta-analyses. In: Higgins JP, Green S, editor(s). Cochrane Handbook for Systematic Reviews of Interventions Version 5.1.0 (updated March 2011). The Cochrane Collaboration, 2011. Available from www.handbook.cochrane.org.

\section{Dyken 1993}

Dyken ML. Controversies in stroke: past and present. New England Journal of Medicine 1993;24:1-7. 


\section{EC/IC Bypass 1985}

The EC/IC Bypass Study Group. Failure of extracranialintracranial arterial bypass to reduce the risk of ischemic stroke. New England Journal of Medicine 1985;313:1191-200.

\section{Eliasziw 1994}

Eliasziw M, Streifler JY, Fox AJ, Hacjinski VC, Ferguson GG, Barnett HJM. Significance of plaque ulceration in symptomatic patients with high grade stenosis. Stroke 1994;25:304-8.

\section{ESVS 2018}

Naylor AR, Ricco JB, de Borst GJ, Debus S, de Haro J, Halliday A, et al. Editor's Choice - Management of atherosclerotic carotid and vertebral artery disease: 2017 clinical practice guidelines of the European Society for Vascular Surgery (ESVS). European Journal of Vascular and Endovascular Surgery 2018;55(1):3-81.

\section{Farrell 1991}

Farrell B, Godwin J, Richards S, Warlow C. The United Kingdom transient ischaemic attack (UK-TIA) aspirin trial: finalresults. Journal of Neurology, Neurosurgery and Psychiatry 1991;54(12):1044-54.

\section{Fieschi 1989}

Fieschi C, Argentino C, Lenzi GL, Sacchetti ML, Toni D, Bozzao L. Clinical and instrumental evaluation of patients with ischemic stroke within the first six hours. Journal of Neurological Science 1989;91:311-21.

\section{GRADEpro GDT [Computer program]}

McMaster University (developed by Evidence Prime) GRADEpro GDT. Version accessed 18 January 2017. Hamilton (ON): McMaster University (developed by Evidence Prime), 2015. Available at gradepro.org.

\section{Guay 2012}

Guay J, Ochroch EA. Carotid endarterectomy plus medical therapy or medical therapy alone for carotid artery stenosis in symptomatic or asymptomatic patients: a metaanalysis. Journal of Cardiothoracic and Vascular Anesthesia 2012;26:835-44.

\section{Henderson 2000}

Henderson RD, Eliasziw M, Fox AJ, Rothwell PM, Barnett HJM. Angiographically defined collateral circulation and risk of stroke in patients with severe carotid artery stenosis. Stroke 2000;31:128-32.

\section{Higgins 2003}

Higgins JPT, Thompson SG, Deeks JJ, Altman DG. Measuring inconsistency in meta-analysis. BMJ 2003;327:557-60.

\section{Higgins 2019}

Higgins JPT, Thomas J, Chandler J, Cumpston M, Li T, Page MJ, et al, editor(s). Cochrane Handbook for Systematic Reviews of Interventions version 6.0 (updated July 2019). The Cochrane Collaboration, 2019. Available from www.training.cochrane.org/ handbook.

\section{Hsia 1992}

Hsia DC, Krushat M, Moscoe LM. Epidemiology of carotid endarterectomies among Medicare beneficiaries. Journal of Vascular Surgery 1992;16:201-8.

\section{Kappelle 1999}

Kappelle LJ, Eliasziw M, Fox AJ, Sharpe BL, Barnett HJM. Importance of intracranial atherosclerotic disease in patients with symptomatic stenosis of the internal carotid artery. Stroke 1999;30:282-6.

\section{Liu 2012}

Liu X, Zhang S, Liu M, Wang Y, Wu J, Dong Q. Chinese guidelines for endovascular management of ischemic cerebrovascular diseases. Interventional Neurology 2012;1:171-84.

\section{Marquardt 2010}

Marquardt L, Geraghty OC, Mehta Z, Rothwell PM. Low risk of ipsilateral stroke in patients with asymptomatic carotid stenosis on best medical treatment: a prospective, population-based study. Stroke 2010;41:e11-7.

\section{Mohr 1978}

Mohr JP, Caplan LR, Meski JW, Goldstein RJ, Duncan GW, Kistler JP, et al. The Harvard Cooperative Stroke Registry: a prospective registry. Neurology 1978;28:754.

\section{Morgenstern 1997}

Morgenstern LB, Fox AJ, Sharpe BL, Eliasziw M, Barnett HJM, Grotta JC. The risks and benefits of carotid endarterectomy in patients with near occlusion of the carotid artery. Neurology 1997;48:911-5.

\section{National Vascular Registry 2019}

Waton S, Johal A, Heikkila K, Cromwell D, Clinical Effectiveness Unit, The Royal College of Surgeons of England. National Vascular Registry 2019 Annual Report. www.hqip.org.uk/ resource/national-vascular-registry-2019-annual-report/ \#.Xh6GrcgzY2w (accessed 15 January 2020).

\section{Pokras 1988}

Pokras R, Dyken ML. Dramatic changes in the performance of endarterectomy for diseases of the extracranial arteries of the head. Stroke 1988;19:1289-90.

\section{Rerkasem 2009}

Rerkasem K, Rothwell PM. Systematic review of the operative risks of carotid endarterectomy for recently symptomatic stenosis in relation to the timing of surgery. Stroke 2009;40:e564-72.

\section{Review Manager 2014 [Computer program]}

Nordic Cochrane Centre, The Cochrane Collaboration Review Manager 5 (RevMan 5). Version 5.3. Copehagen: Nordic Cochrane Centre, The Cochrane Collaboration, 2014.

\section{Rothwell 1997}

Rothwell PM, Slattery J, Warlow CP. A systematic review of clinical and angiographic predictors of stroke and death due to carotid endarterectomy. BMJ 1997;315:1571-7. 


\section{Rothwell 1999}

Rothwell PM, Warlow CP, on behalf of the European Carotid Surgery Trialists' Collaborative Group. Prediction of benefit from carotid endarterectomy in individual patients: a risk modelling study. Lancet 1999;353:2105-10.

\section{Rothwell 2003}

Rothwell PM, Eliasziw M, Gutnikov SA, Fox AJ, Taylor DW, Mayberg MR, Carotid Endarterectomy Trialists' Collaboration. Analysis of pooled data from the randomised controlled trials of endarterectomy for symptomatic carotid stenosis. Lancet 2003;361:107-16.

\section{Rothwell 2004}

Rothwell PM, Eliasziw M, Gutnikov SA, Warlow CP, Barnett HJ, Carotid Endarterectomy Trialists' Collaboration. Endarterectomy for symptomatic carotid stenosis in relation to clinical subgroups and timing of surgery. Lancet 2004;363:915-24.

\section{Sacco 1982}

Sacco RL, Wolf PA, Cannel WB, McNamara PM. Survival and recurrence following stroke: the Framingham Study. Stroke 1982;13:290-5.

\section{Schünemann 2011}

Schünemann HJ, Oxman AD, Vist GE, Higgins JPT, Deeks JJ, Glasziou P, et al. Chapter 12: Interpreting results and drawing conclusions. In: Higgins JPT, Green S, editor(s). Cochrane Handbook for Systematic Reviews of Interventions Version 5.1.0 (updated March 2011). The Cochrane Collaboration, 2011. Available from www.handbook.cochrane.org.

\section{Soltero 1978}

Soltero I, Lin K, Cooper R. Trends in mortality from cerebrovascular diseases in the United States 1962-1975. Stroke 1978;9:549.

\section{CHARACTERISTICS OF STUDIES}

Characteristics of included studies [ordered by study ID]

\section{SPSS 1999}

SPSS Inc. SPSS Base 10.0 for Windows User's Guide. SPSS Base 10.0 for Windows User's Guide 1999:1-548.

\section{Sterne 2011}

Sterne JAC, Egger M, Moher D, editor(s). Chapter 10: Addressing reporting biases. In: Higgins JPT, Green S, editor(s). In: Higgins JPT, Green S, editor(s). Cochrane Handbook for Systematic Reviews of Interventions Version 5.1.0 (updated March 2011). The Cochrane Collaboration, 2011. Available from www.handbook.cochrane.org.

\section{References to other published versions of this review \\ Cina 1999}

Cina C, Clase C, Haynes RB. Carotid endarterectomy for symptomatic carotid stenosis. Cochrane Database of Systematic Reviews 1999, Issue 3. Art. No: CD001081. [DOI: 10.1002/14651858.CD001081]

\section{Orrapin 2017}

Orrapin S, Rerkasem K. Carotid endarterectomy for symptomatic carotid stenosis. Cochrane Database of Systematic Reviews 2017, Issue 6. Art. No: CD001081. [DOI: 10.1002/14651858.CD001081.pub3]

\section{Rerkasem 2011}

Rerkasem K, Rothwell PM. Carotid endarterectomy for symptomatic carotid stenosis. Cochrane Database of Systematic Reviews 2011, Issue 4. Art. No: CD001081. [DOI: 10.1002/14651858.CD001081.pub2]

* Indicates the major publication for the study

\section{ECST 1998}

\section{Study characteristics}

\begin{tabular}{ll} 
Methods & RCT \\
ITT analysis & Not censored at crossover \\
Mean follow-up: 6.1 years \\
Minimum follow-up: 4 months \\
\hline Participants & 3024 participants \\
& Europe and Australia \\
& 97 centres \\
& Sex: either \\
& Age: no restrictions \\
& Qualifying event: ischaemic cerebrovascular event (TIA, retinal infarction or non-disabling ischaemic \\
stroke), ipsilateral to carotid stenosis, within 6 months of randomisation \\
Criteria: inclusion and exclusion criteria with 'uncertainty principle'
\end{tabular}


ECST 1998 (Continued)

Degree of stenosis: $67 \%$ to $99 \%$ (NASCET-measured), $0 \%$ to $99 \%$ (ECST-measured)

Baseline demographics: mean age 63 years, $72 \%$ male, ischaemic heart disease (myocardial infarction or angina) $23 \%$, diabetes $12 \%$

Prior neurological event: TIA 78\%, stroke 50\%

Interventions
sible'
Co-interventions: non-protocolised usual care for both groups
Co-interventions described
Crossover: medical to surgical crossover $3.5 \%$ within 1 year of randomisation; a further $8.3 \%$ of control
patients underwent carotid endarterectomy subsequent to 1 year; surgical to medical crossover $3.4 \%$

\section{Outcomes}

Primary outcome: fatal or disabling ipsilateral ischaemic stroke

Other outcomes: major stroke or surgical death, any major stroke, death from any cause, any major stroke or death, disabling or fatal stroke or surgical death, fatal stroke or surgical death

Stroke was defined as a clinical syndrome characterised by rapidly developing symptoms, signs (or both) of focal, and at times global (applied to patients in deep coma and those with subarachnoid haemorrhage), loss of cerebral function lasting longer than 24 hours or leading to death with no apparent cause other than that of vascular origin

Major stroke was a stroke as defined above, with symptoms lasting longer that 7 days

Disabling stroke was a stroke that after 6 months was associated with disability as recorded on the modified Rankin scale of 3, 4, or 5

Funding source $\quad$ UK Medical Research Council, the European Union Biomed programme, and the University of Oxford
ICRF/MRC Clinical Trial Service Unit, England

$\begin{array}{ll}\text { Notes } & \text { Adequate concealment } \\ & \text { Patients not blinded } \\ & \text { Clinicians not blinded } \\ & \text { External blinded review of outcomes } \\ & \text { Follow-up: } 99.8 \% \\ & \text { Demographics: adequately reported and similar } \\ & \text { Principal investigator: Professor Charles Warlow, Division of Clinical Neurosciences, Western General } \\ & \text { Hospital, Edinburgh EH4 2XU, UK (e-mail: charles.warow@ed.ac.uk) }\end{array}$

\section{Risk of bias}

\begin{tabular}{lll}
\hline Bias & Authors' judgement & Support for judgement \\
\hline $\begin{array}{l}\text { Random sequence genera- } \\
\text { tion (selection bias) }\end{array}$ & Low risk & $\begin{array}{l}\text { Quote: "Patients were randomised from a total of } 80 \text { centres in 14 European } \\
\text { countries by telephone to the MRC/Imperial Cancer Research Fund Clinical Tri- } \\
\text { al Service Unit (CTSU) at the University of Oxford. During the telephone call, } \\
\text { enough information to identify the centre, the doctor, and the patient was en- } \\
\text { tered into the CTSU computer" }\end{array}$ \\
& &
\end{tabular}

$\begin{array}{ll}\begin{array}{l}\text { Allocation concealment } \\ \text { (selection bias) }\end{array} & \text { Low risk } \\ & \begin{array}{l}\text { Quote: "As soon as this entry was complete, a treatment allocation to 'immedi- } \\ \text { ate surgery' or to 'no immediate surgery' was displayed, and that patient was } \\ \text { then irrevocably in the trial, to be followed up until death" }\end{array}\end{array}$

\begin{tabular}{lll}
$\begin{array}{l}\text { Blinding of participants } \\
\text { and personnel (perfor- } \\
\text { mance bias) }\end{array}$ & High risk & $\begin{array}{l}\text { Comment: because of the nature of the intervention (surgical and non-surgical } \\
\text { gll outcomes }\end{array}$ \\
\hline $\begin{array}{l}\text { Blinding of outcome as- } \\
\begin{array}{l}\text { sessment (detection bias) } \\
\text { All outcomes }\end{array}\end{array}$ & Low risk & $\begin{array}{l}\text { Comment: external blinded review of outcomes by independent assessor was } \\
\text { performed, so this was unlikely to influence outcome measurement }\end{array}$ \\
\hline
\end{tabular}


ECST 1998 (Continued)

Incomplete outcome data Low risk Comment: few participants (0.2\%) were lost to follow-up (attrition bias)

All outcomes

\begin{tabular}{ll}
$\begin{array}{l}\text { Selective reporting (re- } \\
\text { porting bias) }\end{array}$ & Low risk Comment: authors published findings on all the study outcomes (predefined) \\
\hline Other bias & Low risk
\end{tabular}

NASCET 1991

\section{Study characteristics}

\begin{tabular}{|c|c|}
\hline Methods & $\begin{array}{l}\text { RCT } \\
\text { ITT analysis } \\
\text { Censored at crossover } \\
\text { Mean follow-up: } 1.5 \text { years for stenosis, ECST-measured } 50 \% \text { to } 99 \% \text {, NASCET-measured } 70 \% \text { to } 99 \% \\
\text { Mean follow-up: } 5 \text { years for NASCET-measured stenosis } 30 \% \text { to } 69 \% \text {, ECST-measured } 58 \% \text { to } 82 \% \\
\text { Minimum follow-up: } 4 \text { months }\end{array}$ \\
\hline Participants & $\begin{array}{l}2926 \text { participants } \\
\text { North America } \\
106 \text { centres } \\
\text { Sex: either } \\
\text { Age: less than } 80 \text { years before 1991, no age limitation afterwards } \\
\text { Qualifying event: ischaemic cerebrovascular event (TIA, transient monocular blindness, or minor non- } \\
\text { disabling ischaemic stroke), ipsilateral to carotid stenosis, within } 4 \text { months of randomisation } \\
\text { Criteria: inclusion and exclusion criteria } \\
\text { Degree of stenosis: } 0 \% \text { to } 99 \% \text { (NASCET equation), } 40 \% \text { to } 99 \% \text { (ECST equation) } \\
\text { Baseline demographics: mean age } 66 \text { years, } 69 \% \text { male, myocardial infarction } 18 \% \text {, angina } 24 \% \text {, dia- } \\
\text { betes } 19 \% \\
\text { Qualifying event: TIA } 68 \% \text {, stroke } 32 \%\end{array}$ \\
\hline
\end{tabular}

\section{Interventions 'Carotid endarterectomy as soon as possible' versus 'no carotid endarterectomy' for stenosis ECST-} measured 30\% to $69 \%$, NASCET-measured $70 \%$ to $99 \%$

'Carotid endarterectomy as soon as possible' versus 'carotid endarterectomy in the event of progression to NASCET-measured $>70 \%$ stenosis, ECST-measured $58 \%$ to $82 \%$ stenosis'.

Co-interventions: protocolised recommendations for both groups

Co-interventions described and similar

Crossover: medical to surgical 6.3\% (ECST-measured 50\% to 99\%, NASCET-measured $70 \%$ to $99 \%$ ); medical to surgical $7 \%$ (ECST-measured $58 \%$ to $82 \%$, NASCET-measured $30 \%$ to $69 \%$ ); a further $7.9 \%$ in this study crossed over in accordance with protocol for progression of stenosis or after a primary event; surgical to medical 0.3\% (ECST-measured 50\% to $99 \%$, NASCET-measured $70 \%$ to $99 \%$ ); surgical to medical $1.9 \%$ (ECST-measured $58 \%$ to $82 \%$, NASCET-measured $30 \%$ to $69 \%$ )

\section{Outcomes Primary outcome: ipsilateral stroke}

Other outcomes: ipsilateral stroke; death; death or stroke; ipsilateral fatal stroke; ipsilateral major stroke; fatal stroke; major stroke; death or major stroke

NINDS stroke definition

Major or disabling stroke was defined as a Rankin score of at least 3 that persisted at 90 days

\begin{tabular}{ll}
\hline Funding source & National Institute of Neurological Disorders and Stroke, USA \\
\hline Notes & Adequate concealment \\
& Patients not blinded \\
& Clinicians not blinded \\
& External blinded review of outcomes \\
\hline
\end{tabular}


NASCET 1991 (Continued)

Follow-up 100\%

Demographics: adequately reported and similar

Principal investigator: Dr Barnett, John P Robarts Research Institute, PO Box 5015, 100 Perth Drive,

London, ON N6A 5K8, Canada

\section{Risk of bias}

\begin{tabular}{lll}
\hline Bias & Authors' judgement & Support for judgement \\
\hline $\begin{array}{l}\text { Random sequence genera- } \\
\text { tion (selection bias) }\end{array}$ & Low risk & Quote: "Patients were randomly assigned to medical or surgical therapy" \\
\hline $\begin{array}{l}\text { Allocation concealment } \\
\text { (selection bias) }\end{array}$ & Low risk & $\begin{array}{l}\text { Quote: "Patients were randomly assigned to medical or surgical therapy by } \\
\text { means of a centralized computer-generated algorithm with stratification ac- } \\
\text { cording to center" }\end{array}$ \\
\hline
\end{tabular}

Blinding of participants High risk
and personnel (perfor-

Comment: because of the nature of the intervention (surgical and non-surgical mance bias) groups), this RCT could not be blinded for surgeons or participants

All outcomes

\begin{tabular}{|c|c|c|}
\hline $\begin{array}{l}\text { Blinding of outcome as- } \\
\text { sessment (detection bias) } \\
\text { All outcomes }\end{array}$ & Low risk & $\begin{array}{l}\text { Quote: "Outcome events were assessed in four steps: first, by the participating } \\
\text { neurologist and surgeon; second, by the neurologists at the study data cen- } \\
\text { ter; third, by the members of the steering committee, in a blinded manner; and } \\
\text { fourth, by blinded external adjudicators" }\end{array}$ \\
\hline
\end{tabular}

\begin{tabular}{lll}
\hline $\begin{array}{l}\text { Incomplete outcome data } \\
\text { (attrition bias) }\end{array}$ & Low risk & Comment: no participants were lost to follow-up \\
All outcomes & & \\
\hline $\begin{array}{l}\text { Selective reporting (re- } \\
\text { porting bias) }\end{array}$ & Low risk & Comment: authors published findings on all the study outcomes (predefined)
\end{tabular}

Other bias Low risk

\section{VACSP 1991}

\section{Study characteristics}

\begin{tabular}{ll}
\hline Methods & RCT \\
ITT analysis & Censored at crossover \\
& Mean follow-up: 1 year \\
& Minimum follow-up: not reported \\
\hline Participants & 193 participants \\
USA & 16 centres \\
Sex: male & Age: no age restrictions \\
Qualifying event: ischaemic cerebrovascular event (TIA, transient monocular blindness or small com- \\
pleted stroke), ipsilateral to carotid stenosis, within 4 months of randomisation \\
Criteria: inclusion and exclusion criteria \\
Degree of stenosis: $50 \%$ to $99 \%$ (NASCET-measured), $70 \%$ to $99 \%$ (ECST-measured) \\
Baseline demographics: mean age 65 years, $100 \%$ male, myocardial infarction $37 \%$, angina $47 \%$, dia- \\
betes $30 \%$
\end{tabular}


VACSP 1991 (Continued)

Qualifying event: TIA 76\%, stroke 24\%
'Carotid endarterectomy as soon as possible' versus 'no carotid endarterectomy' for stenosis ECSTmeasured $30 \%$ to $69 \%$, NASCET-measured $70 \%$ to $99 \%$

Co-interventions: protocolised treatment for both groups

Documentation of co-interventions: inadequately described

Crossover: medical to surgical 3\%; surgical to medical 1\% (ECST-measured 50\% to 99\%, NASCET-measured $70 \%$ to $99 \%$ )

\begin{tabular}{|c|c|c|}
\hline \multicolumn{3}{|l|}{ Risk of bias } \\
\hline Bias & Authors' judgement & Support for judgement \\
\hline $\begin{array}{l}\text { Random sequence genera- } \\
\text { tion (selection bias) }\end{array}$ & Low risk & Comment: unconfounded truly randomised controlled trial \\
\hline $\begin{array}{l}\text { Allocation concealment } \\
\text { (selection bias) }\end{array}$ & Unclear risk & Comment: concealment not described \\
\hline $\begin{array}{l}\text { Blinding of participants } \\
\text { and personnel (perfor- } \\
\text { mance bias) } \\
\text { All outcomes }\end{array}$ & High risk & $\begin{array}{l}\text { Comment: because of the nature of the intervention, this RCT could not be } \\
\text { blinded for surgeons or participants }\end{array}$ \\
\hline $\begin{array}{l}\text { Blinding of outcome as- } \\
\text { sessment (detection bias) } \\
\text { All outcomes }\end{array}$ & Low risk & $\begin{array}{l}\text { Comment: external review of outcomes, unlikely to influence outcome mea- } \\
\text { sures }\end{array}$ \\
\hline $\begin{array}{l}\text { Incomplete outcome data } \\
\text { (attrition bias) } \\
\text { All outcomes }\end{array}$ & Low risk & Comment: few participants (5\%) were lost to follow-up \\
\hline $\begin{array}{l}\text { Selective reporting (re- } \\
\text { porting bias) }\end{array}$ & Low risk & Comment: authors published findings on all the study outcomes \\
\hline Other bias & Unclear risk & $\begin{array}{l}\text { Comment: VACSP was stopped after the results of ECSTand NASCET were pub- } \\
\text { lished, given that it was considered unethical to continue to randomise partici- } \\
\text { pants with severe stenosis. However, this sequence of events was appropriate } \\
\text { and is unlikely to have introduced any bias into the results }\end{array}$ \\
\hline
\end{tabular}

Primary outcome: death within 30 days, or ipsilateral cerebral, or retinal infarction, or ipsilateral crescendo TIA

Other outcomes: death within 30 days, ipsilateral major stroke, ipsilateral minor stroke, ipsilateral crescendo TIA

Stroke definitions as in NASCET

\begin{tabular}{ll}
\hline Funding source & Department of Veterans Affairs Cooperative Studies Program, VA Medical Research Service, USA \\
\hline Notes & Concealment not described \\
& Patients not blinded \\
& Clinicians not blinded \\
& External review of outcomes \\
& Follow-up: $95 \%$ \\
& Demographics: adequately reported and similar \\
& Investigator: Dr Mayberg, Department of Neurosurgery, University of Washington, Seattle, USA 98195
\end{tabular}

ECST: European Carotid Surgery Trial

ITT: intention-to-treat 
NASCET: North American Symptomatic Carotid Endarterectomy Trial

NINDS: National Institute of Neurological Disorders and Stroke

$\mathrm{RCT}$ : randomised controlled trial

TIA: transient ischaemic attack

VACSP: Veterans Affairs Cooperative Studies Program

Characteristics of excluded studies [ordered by study ID]

\begin{tabular}{ll}
\hline Study & Reason for exclusion \\
\hline ACST 2004 & This is a trial in asymptomatic patients \\
\hline Arhuidese 2017 & $\begin{array}{l}\text { This is a cohort study of the Vascular Quality Initiative (VQI) database of patients who underwent } \\
\text { carotid endarterectomy or carotid artery stenting after prior ipsilateral carotid endarterectomy be- } \\
\text { tween January } 2003 \text { and April 2015. This is not a trial }\end{array}$
\end{tabular}

$\begin{array}{ll}\text { Benavente } 2001 & \text { This paper presents the prognosis after transient monocular blindness associated with carotid } \\ \text { artery stenosis. This is not a trial }\end{array}$

Bonati 2018 This paper presented the risk of restenosis and stroke after carotid artery stenting or endarterectomy for symptomatic carotid stenosis in the International Carotid Stenting Study

Columbo 2019 This is a comparative analysis of long-term mortality after carotid endarterectomy and carotid stenting. This is not a trial

Dakour 2017 This study is a retrospective study comparing the outcome of patients undergoing carotid endarterectomy and carotid artery stenting between 2009 and 2015

$\begin{array}{ll}\text { Damirel } 2018 & \begin{array}{l}\text { This study shows the comparison of long-term results of carotid endarterectomy for asymptomatic } \\ \text { carotid artery stenosis }\end{array}\end{array}$

\begin{tabular}{ll}
\hline Fields 1968 & This trial included surgery of the aortic arch, vertebral arteries, and asymptomatic patients \\
\hline Huang 2017 & $\begin{array}{l}\text { Clinical data of consecutive patients who underwent CEA between } 2003 \text { and } 2012 \text { for symptomatic } \\
\text { CAS were reviewed and presented. This is not a trial }\end{array}$ \\
\hline
\end{tabular}

Hussain 2018 This study presents the long-term outcomes of carotid endarterectomy versus stenting in a multicenter population-based Canadian Study

This paper presented the associations of peioperative variables with the 30 -day risk of stroke or
death in carotid endarterectomy for symptomatic carotid stenosis. This is not a trial

Lichtman 2017 This study is a cross-sectional analysis of Medicare fee-for-service beneficiaries aged 65 years or older from 1999 to 2014 using the Medicare Inpatient and Denominator files in patients undergoing carotid endarterectomy and carotid artery stenting. It is not a randomised controlled trial

\begin{tabular}{ll}
\hline Moore 2019 & This trial randomised to CEA or CAS/angioplasty \\
\hline Muller 2019 & $\begin{array}{l}\text { This paper presented the rate of intracerebral haemorrhage in a trial in which patients were ran- } \\
\text { domised to CAS or CEA for symptomatic carotid stenosis }\end{array}$ \\
\hline Neves 2018 & $\begin{array}{l}\text { This study presented the result of the medical therapy for asymptomatic patients and stent place- } \\
\text { ment for symptomatic patients presenting with carotid artery near-occlusion }\end{array}$ \\
\hline Reiff 2019 & $\begin{array}{l}\text { The aim of the SPACE-2 trial was to compare the stroke preventive effects of best medical treat- } \\
\text { ment alone with that of best medical treatment in combination with CEA or CAS, respectively, in } \\
\text { patients with asymptomatic carotid artery stenosis of } 70 \%\end{array}$ \\
\hline
\end{tabular}




\begin{tabular}{ll}
\hline Study & Reason for exclusion \\
\hline Schmid 2017 & $\begin{array}{l}\text { This paper analysed the predictive factors (age and sex) with CEA for asymptomatic or sympto- } \\
\text { matic stenosis in routine practice: secondary data analysis of the Nationwide German Statutory } \\
\text { Quality Assurance Database from } 2009 \text { to } 2014\end{array}$ \\
\hline Shaw 1984 & $\begin{array}{l}\text { This trial reported on carotid endarterectomy done with the unusual adjunct of femoral-carotid by- } \\
\text { pass and was stopped early because of high postoperative morbidity }\end{array}$ \\
\hline Song 2017 & $\begin{array}{l}\text { This study presented the comparative efficacy and safety of carotid endarterectomy and carotid } \\
\text { angioplasty stenting in the treatment of asymptomatic CAS }\end{array}$ \\
\hline
\end{tabular}

CAS: carotid artery stenosis

CEA: carotid endarterectomy

Characteristics of ongoing studies [ordered by study ID]

\section{ISRCTN97744893}

\begin{tabular}{ll}
\hline Study name & The 2nd European Carotid Surgery Trial (ECST-2) \\
\hline Methods & $\begin{array}{l}\text { A multicentre, randomised, controlled, open, prospective clinical trial with blinded outcome as- } \\
\text { sessment }\end{array}$ \\
\hline Participants & $\begin{array}{l}\text { People with symptomatic or asymptomatic atherosclerotic carotid artery stenosis (> 50\%, NASCET } \\
\text { criteria), suitable for revascularisation with 5-year Carotid Artery Risk (CAR) Score indicating risk< } \\
20 \%\end{array}$ \\
\hline Interventions & $\begin{array}{l}\text { Immediate carotid revascularisation with modern optimised medical treatment or modern opti- } \\
\text { mised medical treatment alone }\end{array}$ \\
\hline Outcomes & $\begin{array}{l}\text { Primary outcome: any stroke at any time, plus non-stroke death occurring within 30 days of revas- } \\
\text { cularisation } \\
\text { Secondary outcome: ipsilateral stroke, myocardial infarction, TIA, or any hospitalisation for vascu- } \\
\text { lar disease during follow-up }\end{array}$ \\
\hline Starting date & \begin{tabular}{l} 
March 2012 \\
\hline Contact information
\end{tabular} \\
\hline Stroke Research Group Institute of Neurology, University College London, Box 6, The National Hos- \\
pital, Queen Square London. WC1N 3BG, UK
\end{tabular}

TIA: transient ischaemic attack

\section{DATA AND ANALYSES}


Comparison 1. Surgery versus no surgery

\begin{tabular}{|c|c|c|c|c|}
\hline $\begin{array}{l}\text { Outcome or subgroup ti- } \\
\text { tle }\end{array}$ & No. of studies & $\begin{array}{l}\text { No. of partici- } \\
\text { pants }\end{array}$ & Statistical method & Effect size \\
\hline $\begin{array}{l}\text { 1.1 Any stroke or operative } \\
\text { death }\end{array}$ & 3 & & Risk Ratio (M-H, Fixed, 95\% Cl) & Subtotals only \\
\hline 1.1.1 Near occlusion & 2 & 271 & Risk Ratio (M-H, Fixed, 95\% Cl) & $0.95[0.59,1.53]$ \\
\hline $1.1 .270 \%$ to $99 \%$ & 3 & 1095 & Risk Ratio (M-H, Fixed, 95\% Cl) & $0.53[0.42,0.67]$ \\
\hline $1.1 .350 \%$ to $69 \%$ & 3 & 1549 & Risk Ratio (M-H, Fixed, 95\% Cl) & $0.77[0.63,0.94]$ \\
\hline $1.1 .430 \%$ to $49 \%$ & 2 & 1429 & Risk Ratio (M-H, Fixed, 95\% Cl) & $0.97[0.79,1.19]$ \\
\hline $1.1 .5<30 \%$ & 2 & 1746 & Risk Ratio (M-H, Fixed, 95\% Cl) & $1.25[0.99,1.56]$ \\
\hline $\begin{array}{l}1.2 \text { Ipsilateral ischaemic } \\
\text { stroke and any operative } \\
\text { stroke or death }\end{array}$ & 3 & & Risk Ratio (M-H, Random, 95\% Cl) & Subtotals only \\
\hline 1.2.1 Near occlusion & 2 & 271 & Risk Ratio (M-H, Random, 95\% Cl) & $1.03[0.57,1.84]$ \\
\hline $1.2 .270 \%$ to $99 \%$ & 3 & 1095 & Risk Ratio (M-H, Random, 95\% Cl) & $0.47[0.25,0.88]$ \\
\hline $1.2 .350 \%$ to $69 \%$ & 3 & 1549 & Risk Ratio (M-H, Random, 95\% Cl) & $0.84[0.60,1.18]$ \\
\hline $1.2 .430 \%$ to $49 \%$ & 2 & 1429 & Risk Ratio (M-H, Random, 95\% Cl) & $0.93[0.62,1.38]$ \\
\hline $1.2 .5<30 \%$ & 2 & 1746 & Risk Ratio (M-H, Random, 95\% Cl) & $1.27[0.80,2.01]$ \\
\hline $\begin{array}{l}\text { 1.3 Disabling or fatal ipsi- } \\
\text { lateral ischaemic or opera- } \\
\text { tive stroke and death }\end{array}$ & 3 & & Risk Ratio (M-H, Fixed, 95\% Cl) & Subtotals only \\
\hline 1.3.1 Near occlusion & 2 & 271 & Risk Ratio (M-H, Fixed, 95\% Cl) & $1.29[0.51,3.27]$ \\
\hline $1.3 .270 \%$ to $99 \%$ & 3 & 1095 & Risk Ratio (M-H, Fixed, 95\% Cl) & $0.40[0.26,0.64]$ \\
\hline $1.3 .350 \%$ to $69 \%$ & 2 & 1502 & Risk Ratio (M-H, Fixed, 95\% Cl) & $0.73[0.46,1.15]$ \\
\hline $1.3 .430 \%$ to $49 \%$ & 2 & 1429 & Risk Ratio (M-H, Fixed, 95\% Cl) & $0.96[0.60,1.54]$ \\
\hline $1.3 .5<30 \%$ & 2 & 1746 & Risk Ratio (M-H, Fixed, 95\% Cl) & $1.72[0.99,2.96]$ \\
\hline
\end{tabular}


Analysis 1.1. Comparison 1: Surgery versus no surgery, Outcome 1: Any stroke or operative death

\begin{tabular}{|c|c|c|c|c|c|c|c|}
\hline & \multicolumn{2}{|c|}{ Surgery } & \multicolumn{2}{|c|}{ No surgery } & \multicolumn{2}{|r|}{ Risk Ratio } & Risk Ratio \\
\hline & Events & Total & Events & Tot: & Weigh & M-H, Fixed, 95\% & M-H, Fixed, 95\% \\
\hline
\end{tabular}

1.1.1 Near occlusion NASCET 1991

ECST 1998

Subtotal (95\% CI)

16

16

79

19

9

$67 \quad 73.3 \%$

Total events:

157

32

157

6

$47 \quad 26.7 \%$

$114 \quad \mathbf{1 0 0 . 0} \%$

Heterogeneity: $\mathrm{Chi}^{2}=2.35, \mathrm{df}=1(\mathrm{P}=0.13) ; \mathrm{I}^{2}=57 \%$

Test for overall effect: $\mathrm{Z}=0.20(\mathrm{P}=0.84)$

\subsection{2 $70 \%$ to $99 \%$}

ECST 1998

NASCET 1991

VACSP 1991

Subtotal (95\% CI)

Total events:

$\begin{array}{rr}30 & 257 \\ 54 & 261 \\ 6 & 71 \\ & \mathbf{5 8 9}\end{array}$

$\begin{array}{rrr}55 & 172 & 41.6 \% \\ 88 & 264 & 55.2 \% \\ 5 & 70 & 3.2 \% \\ & \mathbf{5 0 6} & \mathbf{1 0 0 . 0 \%}\end{array}$

Heterogeneity: $\mathrm{Chi}^{2}=6.35, \mathrm{df}=2(\mathrm{P}=0.04) ; \mathrm{I}^{2}=68 \%$

Test for overall effect: $\mathrm{Z}=5.40(\mathrm{P}<0.00001)$

$1.1 .350 \%$ to $69 \%$

$\begin{array}{lrrrrr}\text { NASCET 1991 } & 85 & 428 & 112 & 428 & 63.6 \% \\ \text { ECST 1998 } & 59 & 380 & 53 & 266 & 35.4 \% \\ \text { VACSP 1991 } & 2 & 20 & 2 & 27 & 1.0 \% \\ \text { Subtotal (95\% CI) } & & \mathbf{8 2 8} & & \mathbf{7 2 1} & \mathbf{1 0 0 . 0 \%} \\ \text { Total events: } & 146 & & 167 & & \end{array}$

146

Heterogeneity: $\mathrm{Chi}^{2}=0.36, \mathrm{df}=2(\mathrm{P}=0.83) ; \mathrm{I}^{2}=0 \%$

Test for overall effect: $\mathrm{Z}=2.56(\mathrm{P}=0.01)$

\subsection{4 $30 \%$ to $49 \%$}

NASCET 1991

ECST 1998

103

$48 \quad 302$

111

$477 \quad 75.3 \%$

$185 \quad 24.7 \%$

$662100.0 \%$

Subtotal (95\% CI)

151

767 140

Heterogeneity: $\mathrm{Chi}^{2}=0.07, \mathrm{df}=1(\mathrm{P}=0.80) ; \mathrm{I}^{2}=0 \%$

Test for overall effect: $\mathrm{Z}=0.32(\mathrm{P}=0.75)$

\section{$\mathbf{1 . 1 . 5}<30 \%$}

NASCET 1991

ECST 1998

Subtotal (95\% CI)

Total events:

$\begin{array}{rr}44 & 212 \\ 123 & 783 \\ & \mathbf{9 9 5}\end{array}$

40

64

$213 \quad 34.5 \%$

$538 \quad 65.5 \%$

$751 \quad \mathbf{1 0 0 . 0} \%$

167 104

Heterogeneity: $\mathrm{Chi}^{2}=0.54, \mathrm{df}=1(\mathrm{P}=0.46) ; \mathrm{I}^{2}=0 \%$

Test for overall effect: $\mathrm{Z}=1.90(\mathrm{P}=0.06)$
$0.71[0.40,1.28]$

$1.61[0.68,3.82]$

$0.95[0.59,1.53]$

$0.37[0.24,0.55]$ $0.62[0.46,0.83]$

$1.18[0.38,3.70]$

$0.53[0.42,0.67]$

$0.76[0.59,0.97]$

$0.78[0.56,1.09]$

$1.35[0.21,8.78]$

$0.77[0.63,0.94]$

$0.95[0.75,1.20]$ $1.01[0.66,1.55]$

$0.97[0.79,1.19]$

$1.11[0.75,1.62]$

$1.32[1.00,1.75]$

1.25 [0.99, 1.56]

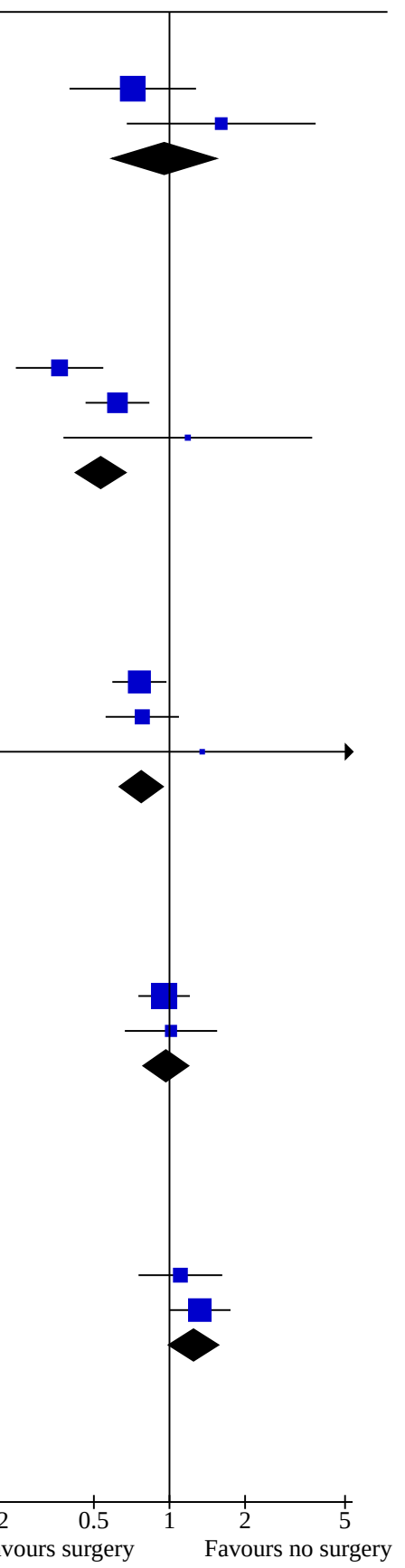




\section{Analysis 1.2. Comparison 1: Surgery versus no surgery, Outcome}

\section{2: Ipsilateral ischaemic stroke and any operative stroke or death}

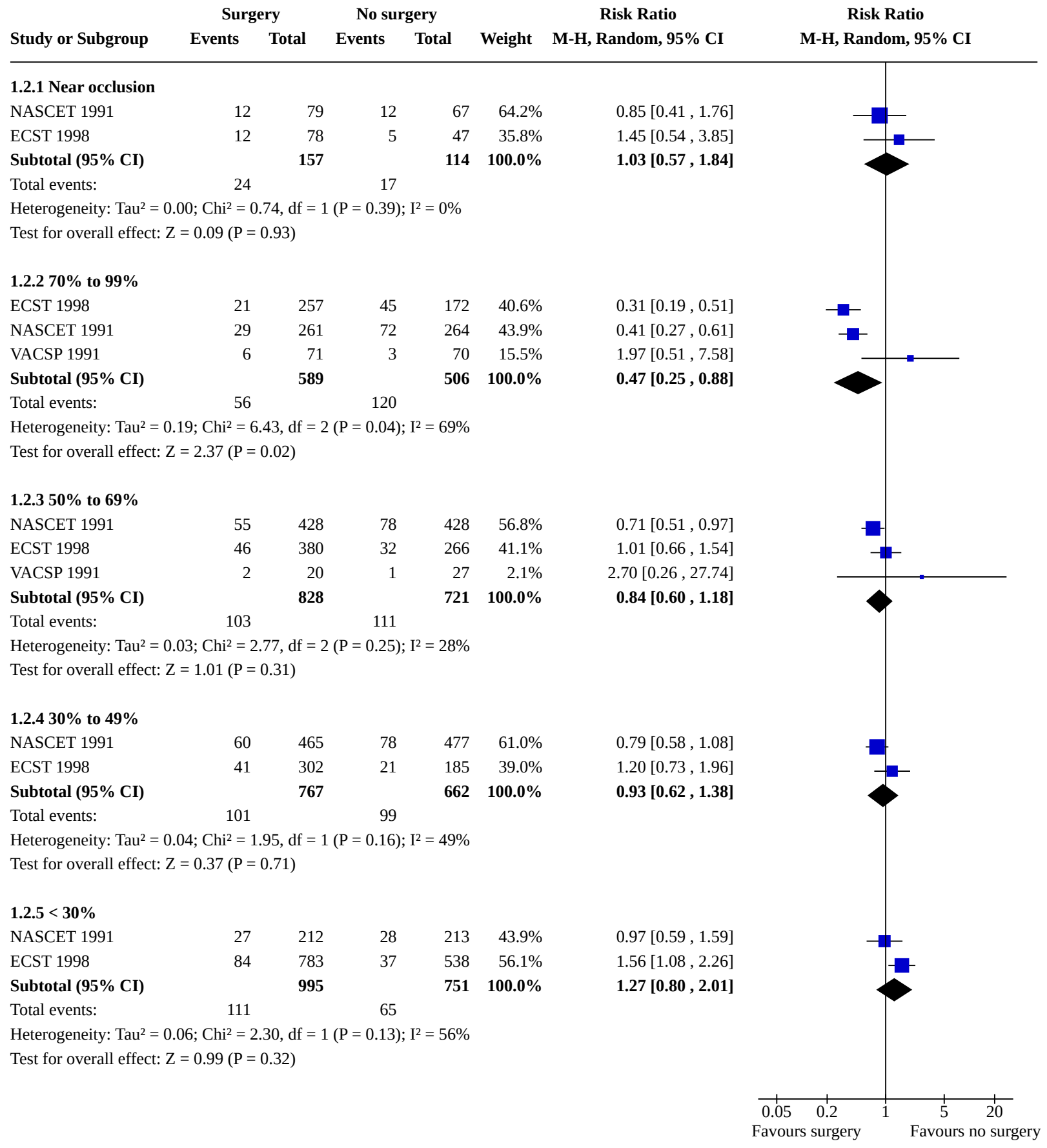


Analysis 1.3. Comparison 1: Surgery versus no surgery, Outcome 3: Disabling or fatal ipsilateral ischaemic or operative stroke and death

\begin{tabular}{|c|c|c|c|c|c|c|}
\hline \multirow[b]{2}{*}{ Study or Subgroup } & \multicolumn{2}{|c|}{ Surgery } & \multicolumn{2}{|c|}{ No surgery } & \multirow[b]{2}{*}{ Weight } & \multirow{2}{*}{$\begin{array}{c}\text { Risk Ratio } \\
\text { I, Fixed, 95\% CI }\end{array}$} \\
\hline & Events & Total & Events & Total & & \\
\hline \multicolumn{7}{|l|}{ 1.3.1 Near occlusion } \\
\hline ECST 1998 & 6 & 78 & 1 & 47 & $16.1 \%$ & $3.62[0.45,29]$. \\
\hline NASCET 1991 & 6 & 79 & 6 & 67 & $83.9 \%$ & $0.85[0.29,2$. \\
\hline Subtotal (95\% CI) & & 157 & & 114 & $100.0 \%$ & $1.29[0.51,3.2$ \\
\hline
\end{tabular}

Total events: $12 \quad 7$

Heterogeneity: $\mathrm{Chi}^{2}=1.52, \mathrm{df}=1(\mathrm{P}=0.22) ; \mathrm{I}^{2}=34 \%$

Test for overall effect: $\mathrm{Z}=0.55(\mathrm{P}=0.59)$

\subsection{2 $70 \%$ to $99 \%$}

$\begin{array}{lrrrrr}\text { ECST 1998 } & 12 & 257 & 20 & 172 & 41.8 \% \\ \text { NASCET 1991 } & 10 & 261 & 33 & 264 & 57.3 \% \\ \text { VACSP 1991 } & 3 & 71 & 0 & 70 & 0.9 \% \\ \text { Subtotal (95\% CI) } & & \mathbf{5 8 9} & & \mathbf{5 0 6} & \mathbf{1 0 0 . 0 \%} \\ \text { Total events: } & 25 & & 53 & & \end{array}$

$0.40[0.20,0.80]$

$0.31[0.15,0.61]$

$6.90[0.36,131.23]$

$0.40[0.26,0.64]$

Heterogeneity: $\mathrm{Chi}^{2}=4.19, \mathrm{df}=2(\mathrm{P}=0.12) ; \mathrm{I}^{2}=52 \%$

Test for overall effect: $\mathrm{Z}=3.86(\mathrm{P}=0.0001)$

$1.3 .350 \%$ to $69 \%$

ECST 1998

NASCET 1991

Subtotal (95\% CI)

Total events:

\section{4}

$11 \quad 428$

18

$266 \quad 50.2 \%$

$428 \quad 49.8 \%$

$694100.0 \%$

35

808

Heterogeneity: $\mathrm{Chi}^{2}=1.49, \mathrm{df}=1(\mathrm{P}=0.22) ; \mathrm{I}^{2}=33 \%$

Test for overall effect: $\mathrm{Z}=1.37(\mathrm{P}=0.17)$

\section{$1.3 .430 \%$ to $49 \%$}

\section{ECST 1998}

NASCET 1991

Subtotal (95\% CI)

$\begin{array}{lll}18 & 302 & 10 \\ 19 & 465 & 22 \\ & 767 & \end{array}$

$\begin{array}{rr}185 & 36.3 \% \\ 477 & 63.7 \% \\ \mathbf{6 6 2} & \mathbf{1 0 0 . 0} \%\end{array}$

$1.10[0.52,2.34]$ $0.89[0.49,1.61]$ $0.96[0.60,1.54]$
$0.93[0.52,1.68]$

$0.52[0.26,1.07]$

$0.73[0.46,1.15]$

\section{Total events:}

$37 \quad 32$

Heterogeneity: $\mathrm{Chi}^{2}=0.20, \mathrm{df}=1(\mathrm{P}=0.66) ; \mathrm{I}^{2}=0 \%$

Test for overall effect: $\mathrm{Z}=0.15(\mathrm{P}=0.88)$

\section{$1.3 .5<30 \%$}

ECST 1998

NASCET 1991

Subtotal (95\% CI)

$\begin{array}{rr}36 & 783 \\ 6 & 212 \\ & \mathbf{9 9 5}\end{array}$

14

$538 \quad 80.6 \%$

Total events:

42

$213 \quad 19.4 \%$

$1.77[0.96,3.24]$

$1.51[0.43,5.26]$

Heterogeneity: $\mathrm{Chi}^{2}=0.05, \mathrm{df}=1(\mathrm{P}=0.82) ; \mathrm{I}^{2}=0 \%$

Test for overall effect: $\mathrm{Z}=1.94(\mathrm{P}=0.05)$

Risk Ratio

M-H, Fixed, 95\% CI 
Comparison 2. Subgroup analyses (5-year cumulative risk of ipsilateral carotid ischaemic stroke, and any stroke or death within 30 days after surgery, according to 3 variables in patients with $>50 \%$ carotid stenosis in ECST and NASCET)

\begin{tabular}{|c|c|c|c|c|}
\hline $\begin{array}{l}\text { Outcome or sub- } \\
\text { group title }\end{array}$ & No. of studies & $\begin{array}{l}\text { No. of partici- } \\
\text { pants }\end{array}$ & Statistical method & Effect size \\
\hline $2.1 \mathrm{Sex}$ & 2 & & Risk Difference (M-H, Fixed, 95\% CI) & Subtotals only \\
\hline 2.1.1 Men & 2 & 1886 & Risk Difference (M-H, Fixed, 95\% CI) & $-0.10[-0.13,-0.06]$ \\
\hline 2.1.2 Women & 2 & 832 & Risk Difference (M-H, Fixed, 95\% Cl) & $-0.03[-0.07,0.02]$ \\
\hline 2.2 Age (years) & 2 & & Risk Difference (M-H, Fixed, 95\% CI) & Subtotals only \\
\hline $2.2 .1<65$ & 2 & 1281 & Risk Difference (M-H, Fixed, 95\% Cl) & $-0.05[-0.09,-0.01]$ \\
\hline 2.2 .265 to 74 & 2 & 1143 & Risk Difference (M-H, Fixed, 95\% Cl) & $-0.07[-0.12,-0.03]$ \\
\hline $2.2 .3>75$ & 2 & 294 & Risk Difference (M-H, Fixed, 95\% Cl) & $-0.17[-0.26,-0.09]$ \\
\hline $\begin{array}{l}2.3 \text { Time since last } \\
\text { event (weeks) }\end{array}$ & 2 & & Risk Difference $(\mathrm{M}-\mathrm{H}$, Fixed, 95\% Cl) & Subtotals only \\
\hline $2.3 .1<2$ & 2 & 624 & Risk Difference (M-H, Fixed, 95\% CI) & $-0.17[-0.24,-0.11]$ \\
\hline 2.3 .22 to 4 & 2 & 483 & Risk Difference (M-H, Fixed, 95\% CI) & $-0.09[-0.15,-0.02]$ \\
\hline 2.3 .34 to 12 & 2 & 1058 & Risk Difference (M-H, Fixed, 95\% CI) & $-0.05[-0.09,-0.01]$ \\
\hline $2.3 .4>12$ & 2 & 553 & Risk Difference (M-H, Fixed, 95\% Cl) & $0.00[-0.06,0.06]$ \\
\hline
\end{tabular}


Analysis 2.1. Comparison 2: Subgroup analyses (5-year cumulative risk of ipsilateral carotid ischaemic stroke, and any stroke or death within $\mathbf{3 0}$ days after surgery, according to 3 variables in patients with $>50 \%$ carotid stenosis in ECST and NASCET), Outcome 1: Sex

\begin{tabular}{lccccccc} 
& \multicolumn{2}{c}{ Surgery } & \multicolumn{2}{c}{ No surgery } & \multicolumn{2}{c}{ Risk Difference } & Risk Difference \\
Study or Subgroup & Events & Total & Events & Total & Weight & M-H, Fixed, 95\% CI & M-H, Fixed, 95\% CI
\end{tabular}

\subsubsection{Men}

ECST 1998

NASCET 1991

Subtotal (95\% CI)

Total events:

Heterogeneity: $\mathrm{Chi}^{2}=0.20, \mathrm{df}=1(\mathrm{P}=0.66) ; \mathrm{I}^{2}=0 \%$

Test for overall effect: $\mathrm{Z}=5.60(\mathrm{P}<0.00001)$

\subsubsection{Women}

ECST 1998

NASCET 1991

Subtotal (95\% CI)

32

31

211
250
$\mathbf{4 6 1}$

63

Heterogeneity: $\mathrm{Chi}^{2}=1.27, \mathrm{df}=1(\mathrm{P}=0.26) ; \mathrm{I}^{2}=21 \%$

Test for overall effect: $\mathrm{Z}=1.01(\mathrm{P}=0.31)$
$-0.09[-0.14,-0.04]$

$-0.10[-0.15,-0.06]$

$-0.10[-0.13,-0.06]$

$873 \quad 100.0 \%$

184

$\begin{array}{rrr}22 & 152 & 43.1 \% \\ 38 & 219 & 56.9 \% \\ & \mathbf{3 7 1} & \mathbf{1 0 0 . 0 \%} \\ 60 & & \end{array}$

$0.01[-0.07,0.08]$

$-0.05[-0.11,0.02]$

$-0.03[-0.07,0.02]$

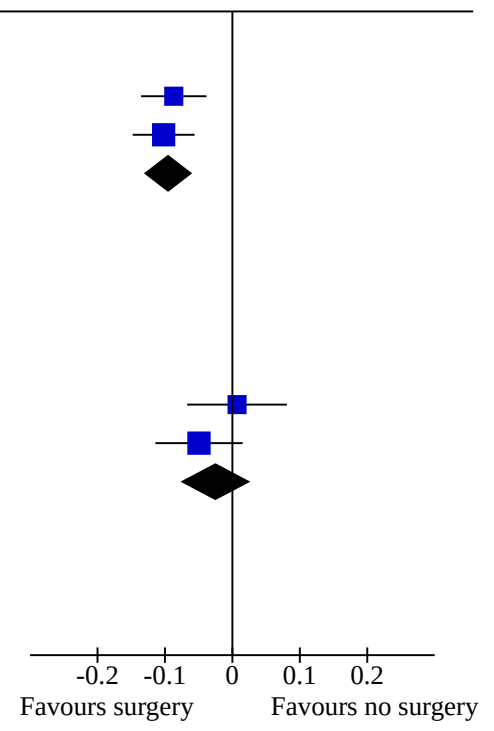


Analysis 2.2. Comparison 2: Subgroup analyses (5-year cumulative risk of ipsilateral carotid ischaemic stroke, and any stroke or death within 30 days after surgery, according to 3 variables in patients with $>50 \%$ carotid stenosis in ECST and NASCET), Outcome 2: Age (years)

\begin{tabular}{lccccccc} 
& \multicolumn{2}{c}{ Surgery } & \multicolumn{2}{c}{ No surgery } & \multicolumn{2}{c}{ Risk Difference } & Risk Difference \\
Study or Subgroup & Events & Total & Events & Total & Weight & M-H, Fixed, 95\% CI & M-H, Fixed, 95\% CI
\end{tabular}

\subsection{1 $<65$}

ECST 1998

NASCET 1991

Subtotal (95\% CI)

Total events:

Heterogeneity: $\mathrm{Chi}^{2}=0.24, \mathrm{df}=1(\mathrm{P}=0.63) ; \mathrm{I}^{2}=0 \%$

Test for overall effect: $\mathrm{Z}=2.55(\mathrm{P}=0.01)$

\subsubsection{5 to 74}

ECST 1998

NASCET 1991

Subtotal (95\% CI)

Total events:

$\begin{array}{rl}33 & 283 \\ 41 & 318 \\ & \mathbf{6 0 1}\end{array}$

74

Heterogeneity: $\mathrm{Chi}^{2}=1.63, \mathrm{df}=1(\mathrm{P}=0.20) ; \mathrm{I}^{2}=39 \%$

Test for overall effect: $\mathrm{Z}=3.34(\mathrm{P}=0.0008)$

\subsection{3 $>75$}

ECST 1998

NASCET 1991

Subtotal (95\% CI)

$6 \quad 47-9$

Total events:

$9 \quad 95$

142

15

Heterogeneity: $\mathrm{Chi}^{2}=0.02, \mathrm{df}=1(\mathrm{P}=0.89) ; \mathrm{I}^{2}=0 \%$

Test for overall effect: $\mathrm{Z}=3.89(\mathrm{P}=0.0001)$

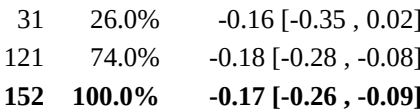

$-0.04[-0.10,0.03]$ -0.09 [-0.15, - 0.04$]$ $-0.07[-0.12,-0.03]$

$362 \quad 60.6 \%$

$542 \quad 100.0 \%$

$-0.06[-0.11,-0.01]$

$-0.04[-0.10,0.02]$

$-0.05[-0.09,-0.01]$

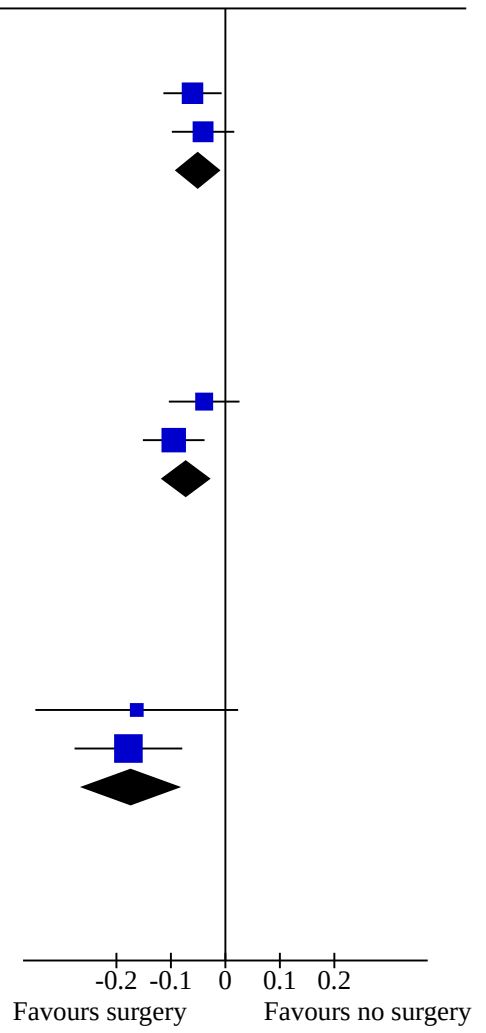


Analysis 2.3. Comparison 2: Subgroup analyses (5-year cumulative risk of ipsilateral carotid ischaemic stroke, and any stroke or death within 30 days after surgery, according to 3 variables in patients with $>50 \%$ carotid stenosis in ECST and NASCET), Outcome 3: Time since last event (weeks)

\begin{tabular}{lccccccc} 
& \multicolumn{2}{c}{ Surgery } & \multicolumn{2}{c}{ No surgery } & \multicolumn{2}{c}{ Risk Difference } & Risk Difference \\
Study or Subgroup & Events & Total & Events & Total & Weight & M-H, Fixed, 95\% CI & M-H, Fixed, 95\% CI
\end{tabular}

\begin{tabular}{llllrrr}
\hline $\mathbf{2 . 3 . 1}<\mathbf{2}$ & & & & & & \\
ECST 1998 & 13 & 112 & 26 & 75 & $29.1 \%$ & $-0.23[-0.35,-0.11]$ \\
NASCET 1991 & 27 & 213 & 62 & 224 & $70.9 \%$ & $-0.15[-0.22,-0.08]$ \\
Subtotal (95\% CI) & & $\mathbf{3 2 5}$ & & $\mathbf{2 9 9}$ & $\mathbf{1 0 0 . 0 \%}$ & $\mathbf{- 0 . 1 7}[\mathbf{- 0 . 2 4}, \mathbf{- 0 . 1 1}]$
\end{tabular}

Total events: $\quad 40 \quad 88$

Heterogeneity: Chi $^{2}=1.22, \mathrm{df}=1(\mathrm{P}=0.27) ; \mathrm{I}^{2}=18 \%$

Test for overall effect: $\mathrm{Z}=5.37(\mathrm{P}<0.00001)$

\subsubsection{2 to 4}

ECST 1998

NASCET 1991

Subtotal (95\% CI)

$\begin{array}{ll}17 & 136 \\ 14 & 132 \\ & \mathbf{2 6 8}\end{array}$

13
31

$81 \quad 43.3 \%$

$-0.04[-0.13,0.06]$

Total events:

$31 \quad 44$

Heterogeneity: $\mathrm{Chi}^{2}=1.79, \mathrm{df}=1(\mathrm{P}=0.18) ; \mathrm{I}^{2}=44 \%$

Test for overall effect: $\mathrm{Z}=2.58(\mathrm{P}=0.010)$

\subsubsection{4 to 12}

ECST 1998

NASCET 1991

Subtotal (95\% CI)

$29 \quad 271 \quad 31$

$\begin{array}{rr}216 & 45.7 \% \\ 282 & 54.3 \% \\ \mathbf{4 9 8} & \mathbf{1 0 0 . 0} \%\end{array}$

$-0.04[-0.10,0.02]$

Total events:

$34 \quad 289$

50

$134 \quad 56.7 \%$

$-0.13[-0.21,-0.04]$

$215 \quad 100.0 \% \quad-0.09[-0.15,-0.02]$

Heterogeneity: $\mathrm{Chi}^{2}=0.30, \mathrm{df}=1(\mathrm{P}=0.58) ; \mathrm{I}^{2}=0 \%$

Test for overall effect: $\mathrm{Z}=2.31(\mathrm{P}=0.02)$

\subsection{4 > 12}

ECST 1998

NASCET 1991

Subtotal (95\% CI)

$\begin{array}{ll}20 & 196 \\ 21 & 125 \\ & \mathbf{3 2 1}\end{array}$

$\begin{array}{rr}113 & 54.0 \% \\ 119 & 46.0 \% \\ \mathbf{2 3 2} & \mathbf{1 0 0 . 0 \%}\end{array}$

$-0.00[-0.08,0.07]$

Total events:

41

$0.01[-0.08,0.10]$

$0.00[-0.06,0.06]$

Heterogeneity: $\mathrm{Chi}^{2}=0.05, \mathrm{df}=1(\mathrm{P}=0.83) ; \mathrm{I}^{2}=0 \%$

Test for overall effect: $\mathrm{Z}=0.05(\mathrm{P}=0.96)$

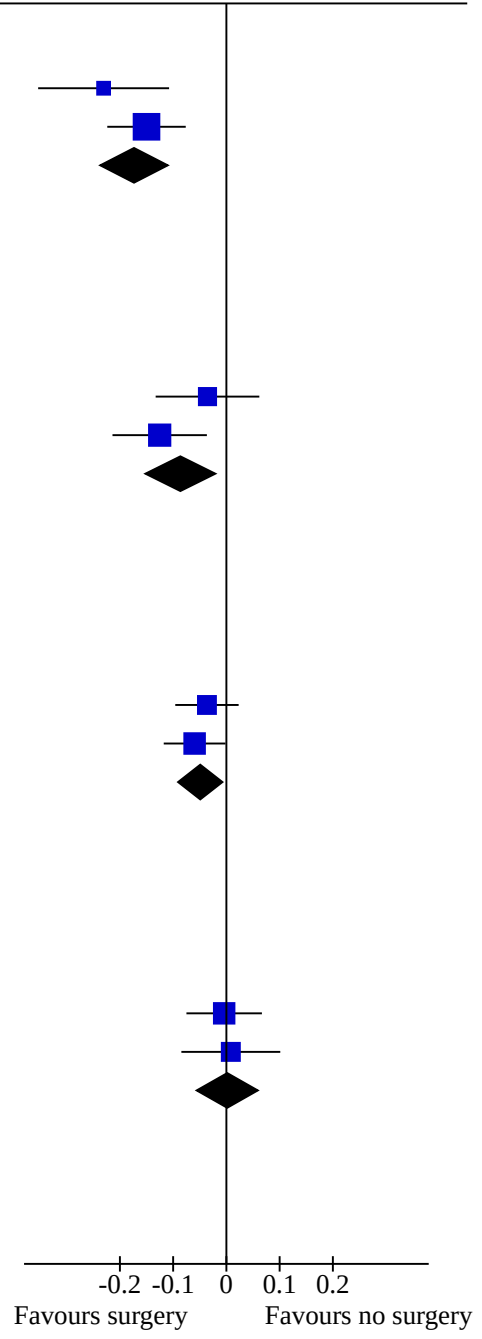




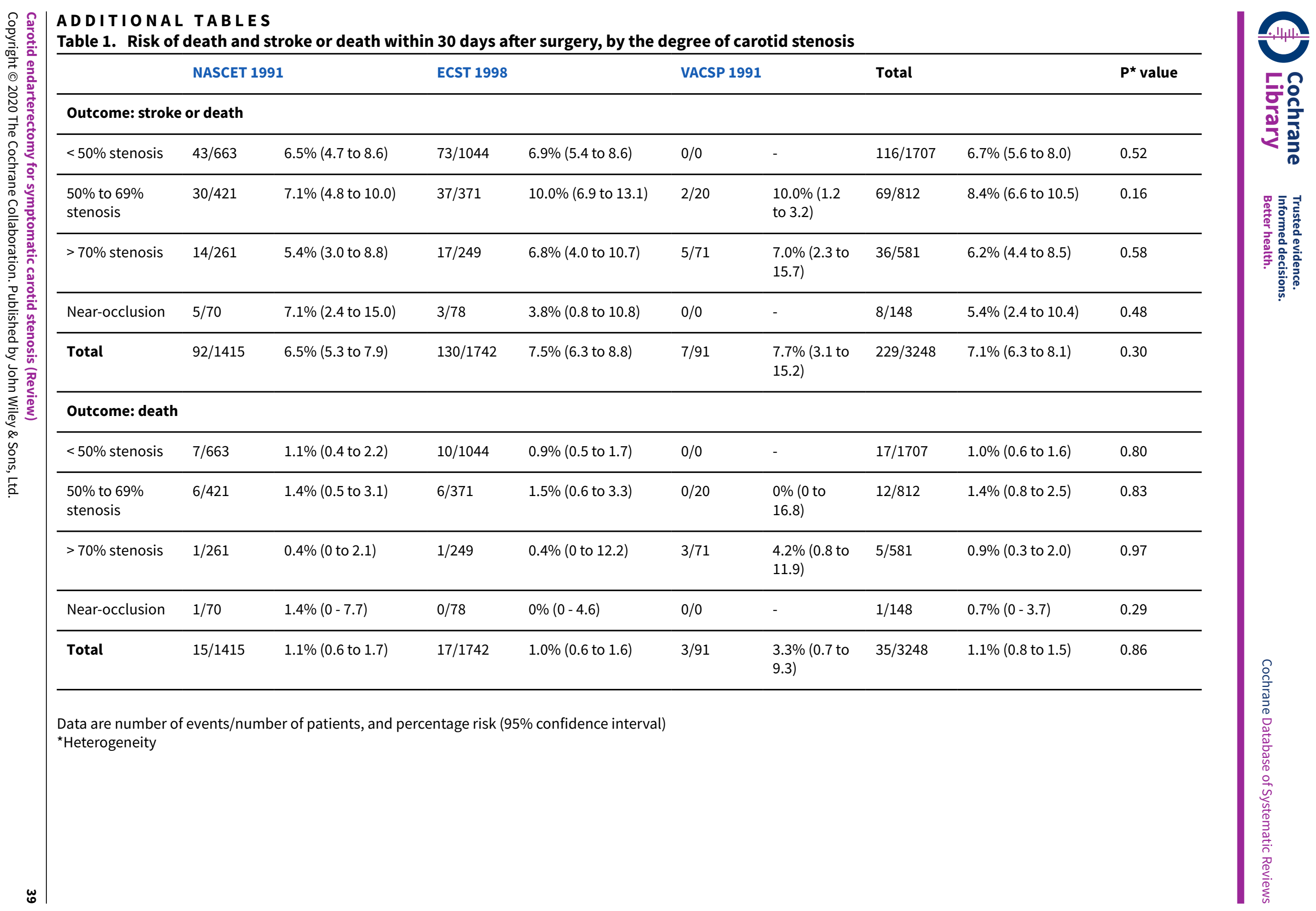


Table 2. The relationships between each subgroup variable and risk of each of the main elements of the primary outcome measure in medical arm.

\begin{tabular}{|c|c|c|c|c|}
\hline \multicolumn{2}{|l|}{ Subgroups } & \multicolumn{3}{|c|}{ Ipsilaterial ischaemic stroke in medical group } \\
\hline & & HR & $(95 \% \mathrm{Cl})$ & $\mathbf{P}$ \\
\hline \multicolumn{5}{|c|}{ Predefined participant subgroups } \\
\hline \multicolumn{2}{|c|}{ Sex (women versus men) } & 0.79 & (0.64 to 0.97$)$ & 0.03 \\
\hline \multirow[t]{3}{*}{ Age } & $<65$ years & 1.00 & & 0.001 \\
\hline & 65 to 74 years & 1.23 & (1.00 to 1.51 ) & \\
\hline & $75+$ years & 1.70 & (1.28 to 2.56$)$ & \\
\hline \multirow[t]{4}{*}{ Time since last event } & $<2$ weeks & 1.00 & & 0.003 \\
\hline & 2 to 4 weeks & 0.80 & (0.61 to 1.06$)$ & \\
\hline & 4 to 12 weeks & 0.69 & (0.55 to 0.88$)$ & \\
\hline & $>12$ weeks & 0.61 & (0.46 to 0.82$)$ & \\
\hline \multirow{3}{*}{$\begin{array}{l}\text { Primary sympto- } \\
\text { matic event }\end{array}$} & Ocular only & 1.00 & & $<0.001$ \\
\hline & Cerebral TIA & 1.88 & (1.38 to 2.55$)$ & \\
\hline & Stroke & 2.33 & (1.74 to 3.13 ) & \\
\hline \multicolumn{2}{|l|}{ Diabetes } & 1.31 & (1.05 to 1.65$)$ & 0.02 \\
\hline \multicolumn{2}{|c|}{ Irregular or ulcerated plaque } & 1.35 & (1.11 to 1.64$)$ & 0.003 \\
\hline \multicolumn{2}{|c|}{ Contralateral ICA occlusion } & 1.30 & (0.09 to 1.88$)$ & 0.16 \\
\hline \multicolumn{5}{|c|}{ Post-hoc participant subgroups } \\
\hline \multirow{2}{*}{$\begin{array}{l}\text { Duration of cerebral } \\
\text { TIA }\end{array}$} & 1 hour or less & 1.00 & & \\
\hline & $>1$ hour & 1.45 & (1.03 to 2.04$)$ & 0.03 \\
\hline \multicolumn{2}{|l|}{ Previous TIA or stroke } & 1.20 & (0.99 to 1.46$)$ & 0.07 \\
\hline \multicolumn{2}{|l|}{ Myocardial infarction } & 1.40 & (1.11 to 1.77 ) & 0.004 \\
\hline \multicolumn{2}{|l|}{ Angina } & 1.26 & (1.02 to 1.56$)$ & 0.03 \\
\hline \multicolumn{2}{|l|}{ Treated hypertension } & 1.39 & (1.15 to 1.68$)$ & 0.001 \\
\hline \multicolumn{2}{|c|}{ Treated hyperlipidaemia } & 0.78 & (0.62 to 0.98$)$ & 0.03 \\
\hline \multicolumn{2}{|l|}{ Smoking } & 0.96 & (0.80 to 1.16$)$ & 0.70 \\
\hline
\end{tabular}

HR: hazard ratio

ICA: internal carotid artery 
TIA: transient ischaemic attack

Table 3. The relationships between each subgroup variable and risk of each of the main elements of the primary outcome measure in surgical arm

\begin{tabular}{|c|c|c|c|c|}
\hline \multicolumn{2}{|l|}{ Subgroups } & \multicolumn{3}{|c|}{ Perioperative stroke or death in surgery group } \\
\hline & & HR & $(95 \% \mathrm{Cl})$ & $\mathbf{P}$ \\
\hline \multicolumn{5}{|c|}{ Predefined participant subgroups } \\
\hline \multicolumn{2}{|c|}{ Sex (women versus men) } & 1.50 & (1.14 to 1.97$)$ & 0.004 \\
\hline \multirow[t]{3}{*}{ Age } & $<65$ years & 1.00 & & 0.78 \\
\hline & 65 to 74 years & 0.99 & (0.76 to 1.32 ) & \\
\hline & $75+$ years & 0.83 & (0.49 to 1.41$)$ & \\
\hline \multirow[t]{4}{*}{ Time since last event } & $<2$ weeks & 1.00 & & 0.69 \\
\hline & 2 to 4 weeks & 1.22 & (0.78 to 1.90$)$ & \\
\hline & 4 to 12 weeks & 1.14 & (0.77 to 1.68$)$ & \\
\hline & $>12$ weeks & 1.28 & (0.84 to 1.95$)$ & \\
\hline \multirow{3}{*}{$\begin{array}{l}\text { Primary sympto- } \\
\text { matic event }\end{array}$} & Ocular only & 1.00 & & $<0.001$ \\
\hline & Cerebral TIA & 2.62 & (1.68 to 4.09$)$ & \\
\hline & Stroke & 1.91 & (1.22 to 3.01 ) & \\
\hline \multicolumn{2}{|l|}{ Diabetes } & 1.45 & (1.05 to 2.02 ) & 0.03 \\
\hline \multicolumn{2}{|c|}{ Irregular or ulcerated plaque } & 1.37 & (1.03 to 1.82$)$ & 0.03 \\
\hline \multicolumn{2}{|c|}{ Contralateral ICA occlusion } & 2.21 & (1.33 to 3.67$)$ & 0.002 \\
\hline \multicolumn{5}{|c|}{ Post-hoc participant subgroups } \\
\hline \multirow{2}{*}{$\begin{array}{l}\text { Duration of cerebral } \\
\text { TIA }\end{array}$} & 1 hour or less & 1.00 & & \\
\hline & $>1$ hour & 1.24 & (0.81 to 1.92 ) & 0.33 \\
\hline \multicolumn{2}{|l|}{ Previous TIA or stroke } & 1.59 & (1.21 to 2.09 ) & 0.001 \\
\hline \multicolumn{2}{|l|}{ Myocardial infarction } & 0.87 & (0.59 to 1.27 ) & 0.46 \\
\hline \multicolumn{2}{|l|}{ Angina } & 0.67 & (0.47 to 0.97$)$ & 0.03 \\
\hline \multicolumn{2}{|l|}{ Treated hypertension } & 1.33 & (1.02 to 1.74$)$ & 0.04 \\
\hline \multicolumn{2}{|c|}{ Treated hyperlipidaemia } & 1.06 & (0.74 to 1.51$)$ & 0.75 \\
\hline \multicolumn{2}{|l|}{ Smoking } & 0.97 & (0.74 to 1.27 ) & 0.81 \\
\hline
\end{tabular}


HR: hazard ratio

ICA: internal carotid artery

TIA: transient ischaemic attack

Table 4. Significance of treatment-effect modifiers for the relative treatment effect and absolute treatment effect for each of the subgroup variables

Effect of surgery on the risk of the primary outcome ( $P$ value)

\begin{tabular}{|c|c|c|c|}
\hline & \multicolumn{2}{|c|}{ Relative risk reduction } & \multirow{2}{*}{$\begin{array}{l}\text { Absolute reduc- } \\
\text { tion in } 5 \text {-year actu- } \\
\text { arial risk }\end{array}$} \\
\hline & Cox model & $\begin{array}{l}\text { 5-year actuarial } \\
\text { risk }\end{array}$ & \\
\hline \multicolumn{4}{|c|}{ Predefined participant subgroups } \\
\hline Sex & 0.007 & 0.008 & 0.003 \\
\hline Age groups & $\begin{array}{l}0.09 \\
0.05 \text { (trend) }\end{array}$ & 0.04 & 0.03 \\
\hline Time since last event groups & $\begin{array}{l}0.04 \\
0.006 \text { (trend) }\end{array}$ & 0.05 & 0.009 \\
\hline Primary symptomatic event & 0.21 & 0.30 & 0.16 \\
\hline Diabetes & 0.51 & 0.85 & 0.63 \\
\hline Irregular or ulcerated plaque & 0.58 & 0.23 & 0.10 \\
\hline Contralateral ICA occlusion & 0.30 & 0.34 & 0.25 \\
\hline \multicolumn{4}{|c|}{ Post-hoc participant subgroups } \\
\hline Duration of cerebral TIA & 0.44 & 0.47 & 0.42 \\
\hline Previous TIA or stroke & 0.08 & 0.23 & 0.50 \\
\hline Myocardial infarction & 0.06 & 0.02 & 0.01 \\
\hline Angina & 0.08 & 0.11 & 0.06 \\
\hline Treated hypertension & 0.19 & 0.29 & 0.09 \\
\hline Treated hyperlipidaemia & 0.63 & 0.85 & 0.85 \\
\hline Smoking & 0.40 & 0.40 & 0.38 \\
\hline
\end{tabular}

ICA: internal carotid artery

TIA: transient ischaemic attack

\section{APPENDICES}

\section{Appendix 1. Cochrane Central Register of Controlled Trials (CENTRAL) search strategy}

CENTRAL; October 2019, Issue 10 of 12 in the Cochrane Library (searched October 2019) 
ID Search Hits

\#1 [mh^"cerebrovascular disorders"] or [mh^"basal ganglia cerebrovascular disease"] or [mh ^"brain ischemia"] or [mh "brain infarction"] or [mh $\wedge^{\wedge}$ "hypoxia-ischemia, brain"] or [mh $\wedge^{\wedge}$ "ischemic attack, transient"] or [mh $\wedge^{\wedge}$ carotid artery diseases"] or [mh $\wedge^{\wedge}$ carotid artery thrombosis"] or [mh^"carotid artery, internal, dissection"] or [mh^"carotid stenosis"] or [mh "carotid artery injuries"] or [mh^"intracranial arterial diseases"] or [ $\mathrm{mh}^{\wedge}$ "cerebral arterial diseases"] or [mh $\wedge^{\wedge}$ infarction, anterior cerebral artery"] or [mh ^"infarction, middle cerebral artery"] or [mh ^"infarction, posterior cerebral artery"] or [mh "intracranial embolism and thrombosis"] or [mh stroke] or [mh ^"vertebral artery dissection"]

\#2 (isch*emi* near/6 (stroke* or apoplex* or cerebral next vasc* or cerebrovasc ${ }^{\star}$ or cva or attack*))

\#3 ((brain or cerebr ${ }^{\star}$ or cerebell* or vertebrobasil ${ }^{\star}$ or hemispher* or intracran* or intracerebral or infratentorial or supratentorial or middle next cerebr ${ }^{\star}$ or mca* or anterior next circulation) near $/ 5\left(\right.$ isch $^{\star}$ emi $^{\star}$ or infarct ${ }^{\star}$ or thrombo* or emboli*))

\#4 (transient next isch* or TIA or TIAs)

\#5 (carotid near/5 (stenosis or thrombo* or disease* or arter $^{\star}$ or atherosclero* or atheroma* or narrow* or plaque* or occlus ${ }^{\star}$ or occlud ${ }^{\star}$ or constrict* or emboli* or block $\left.{ }^{\star}\right)$ )

$\# 6$ \#1 or \#2 or \#3 or \#4 or \#5

\#7 [mh $\wedge^{\wedge}$ "carotid artery diseases"/SU] or [mh $\wedge^{\wedge}$ carotid artery thrombosis"/SU] or [mh ${ }^{\wedge}$ "carotid artery, internal, dissection"/SU] or [mh $\wedge$ "carotid stenosis"/SU] or [mh "carotid artery injuries"/SU] or [mh "Carotid Arteries"/SU]

\#8 [mh^"Endarterectomy, Carotid"]

\#9 (carotid near/5 (endarterectomy or thromboendarterectomy or surgery or revasculari or eversion))

$\# 10$ CEA

$\# 11$ [mh $\wedge^{\wedge}$ carotid artery diseases"] or [mh ^"carotid artery thrombosis"] or [mh ^"carotid artery, internal, dissection"] or [mh ${ }^{\wedge}$ "carotid stenosis"] or [mh "carotid artery injuries"] or [mh "Carotid Arteries"]

$\# 12$ carotid

\#13 \#11 or \#12

$\# 14\left[\mathrm{mh}^{\wedge}\right.$ Endarterectomy]

$\# 15 \# 13$ and \#14

\#16 \#7 or \#8 or \#9 or \#10 or \#15

$\# 17$ \#6 and \#16

\section{Appendix 2. MEDLINE Ovid search strategy}

MEDLINE Ovid - revised October 2019 (1966 to October 2019)

1. cerebrovascular disorders/ or basal ganglia cerebrovascular disease/ or brain ischemia/ or exp brain infarction/ or hypoxia-ischemia, brain/ or ischemic attack, transient/ or carotid artery diseases/ or carotid artery thrombosis/ or carotid artery, internal, dissection/ or carotid stenosis/ or exp carotid artery injuries/or intracranial arterial diseases/or cerebral arterial diseases/or infarction, anterior cerebral artery/ or infarction, middle cerebral artery/ or infarction, posterior cerebral artery/ or exp "intracranial embolism and thrombosis"/ or exp stroke/ or vertebral artery dissection/

2. (isch?emi\$ adj6 (stroke\$ or apoplex\$ or cerebral vasc\$ or cerebrovasc\$ or cva or attack\$)).tw.

3. ((brain or cerebr\$ or cerebell\$ or vertebrobasil\$ or hemispher\$ or intracran\$ or intracerebral or infratentorial or supratentorial or middle cerebr\$ or mca\$ or anterior circulation) adj5 (isch?emi\$ or infarct\$ or thrombo $\$$ or emboli\$)).tw.

4. (transient isch\$ or TIA or TIAs).tw.

5. (carotid adj5 (stenosis or thrombo $\$$ or disease $\$$ or arter\$ or atherosclero\$ or atheroma or narrow\$ or plaque\$ or occlus\$ or occlud\$ or constrict\$ or emboli* or block\$)).tw.

6. 1 or 2 or 3 or 4 or 5 
7. carotid artery diseases/su or carotid artery thrombosis/su or carotid artery, internal, dissection/su or carotid stenosis/su or exp carotid artery injuries/su or exp Carotid Arteries/su
8. Endarterectomy, Carotid/
9. (carotid adj5 (endarterectomy or thromboendarterectomy or surgery or revasculari\$ or eversion)).tw.
10. CEA.tw.

11. carotid artery diseases/ or carotid artery thrombosis/ or carotid artery, internal, dissection/ or carotid stenosis/ or exp carotid artery injuries/ or exp Carotid Arteries/

12. carotid.tw.

13. 11 or 12

14. Endarterectomy/

15. 13 and 14

16. 7 or 8 or 9 or 10 or 15

17. Randomized Controlled Trials as Topic/

18. random allocation/

19. Controlled Clinical Trials as Topic/

20. control groups/

21. clinical trials as topic/

22. randomized controlled trial.pt.

23. controlled clinical trial.pt.

24. clinical trial.pt.

25. (random\$ or RCT or RCTs).tw.

26. (controlled adj5 (trial\$ or stud\$)).tw.

27. (clinical\$ adj5 trial\$).tw.

28. ((control or treatment or experiment\$ or intervention) adj5 (group\$ or subject\$ or patient\$)).tw.

29. (quasi-random $\$$ or quasi random\$ or pseudo-random\$ or pseudo random\$).tw.

30. ((control or experiment\$ or conservative) adj5 (treatment or therapy or procedure or manage\$)).tw.

31. trial.ti.

32. (assign\$ or allocat\$).tw.

33. controls.tw.

34. or/17-33

35.6 and 16 and 34

36. exp animals/ not humans.sh.

37.35 not 36

38. limit 37 to ed=20160301-20190731

\section{Appendix 3. Embase Ovid search strategy}

Embase Ovid - revised October 2019 (1990 to October 2019)

Carotid endarterectomy for symptomatic carotid stenosis (Review) 
1. cerebrovascular disease/ or brain infarction/ or brain stem infarction/ or cerebellum infarction/ or exp brain ischemia/ or carotid artery disease/ or exp carotid artery obstruction/ or carotid artery injury/ or carotid atherosclerosis/ or cerebral artery disease/ or exp cerebrovascular accident/ or exp occlusive cerebrovascular disease/ or stroke patient/

2. (isch?emi\$ adj6 (stroke\$ or apoplex\$ or cerebral vasc\$ or cerebrovasc\$ or cva or attack\$)).tw.

3. ((brain or cerebr\$ or cerebell\$ or vertebrobasil\$ or hemispher\$ or intracran\$ or intracerebral or infratentorial or supratentorial or middle cerebr\$ or mca\$ or anterior circulation) adj5 (isch?emi\$ or infarct\$ or thrombo $\$$ or emboli\$)).tw.

4. (transient isch\$ or TIA or TIAs).tw.

5. (carotid adj5 (stenosis or thrombo\$ or disease\$ or arter\$ or atherosclero\$ or atheroma\$ or narrow\$ or plaque\$ or occlus\$ or occlud\$ or constrict\$ or emboli* or block\$)).tw.

6. 1 or 2 or 3 or 4 or 5

7. carotid artery disease/su or exp carotid artery obstruction/su or carotid artery injury/su or carotid atherosclerosis/su or exp carotid artery/su

8. carotid endarterectomy/ or carotid artery surgery/

9. (carotid adj5 (endarterectomy or thromboendarterectomy or surgery or revasculari\$ or eversion)).tw.

10. CEA.tw.

11. carotid artery disease/ or exp carotid artery obstruction/ or carotid artery injury/ or carotid atherosclerosis/ or exp carotid artery/

12. carotid.tw.

13. 11 or 12

14. Endarterectomy/

15. 13 and 14

16. 7 or 8 or 9 or 10 or 15

17. Randomized Controlled Trial/ or "randomized controlled trial (topic)"/

18. Randomization/

19. Controlled clinical trial/ or "controlled clinical trial (topic)"/

20. control group/ or controlled study/

21. clinical trial/

22. (random\$ or RCT or RCTs).tw.

23. (controlled adj5 (trial\$ or stud\$)).tw.

24. (clinical\$ adj5 trial\$).tw.

25. ((control or treatment or experiment\$ or intervention) adj5 (group\$ or subject\$ or patient\$)).tw.

26. (quasi-random\$ or quasi random\$ or pseudo-random\$ or pseudo random\$).tw.

27. ((control or experiment\$ or conservative) adj5 (treatment or therapy or procedure or manage\$)).tw.

28. trial.ti.

29. (assign\$ or allocat\$).tw.

30. controls.tw.

31. or/17-30

32. 6 and 16 and 31

Carotid endarterectomy for symptomatic carotid stenosis (Review) 
33. (exp animals/ or exp invertebrate/ or animal experiment/ or animal model/or animal tissue/ or animal cell/ or nonhuman/) not (human/ or normal human/ or human cell/)

\section{32 not 33}

35. limit 34 to $d d=20160301-20190731$

\section{Appendix 4. Search strategies for other databases}

\section{Database: Web of Science Core Collection - Thomson Reuters (2001 to 23 October 2019)}

1. Topic=(Carotid stenosis) AND Topic=(Carotid endarterectomy); Timespan=All Years

Searches of trial registers for ongoing and registered trials

Database: ClinicalTrials.gov (searched 23 Octover 2019)

1. carotid stenosis

2. symptomatic carotid stenosis

3. carotid endarterectomy

4. symptomatic carotid stenosis AND carotid endarterectomy

5. symptomatic AND carotid stenosis AND carotid endarterectomy

Database: WHO International Clinical Trials Registry Platform (ICTRP; searched 23 October 2019)

1. carotid stenosis

2. symptomatic carotid stenosis

3. carotid endarterectomy

4. symptomatic carotid stenosis AND carotid endarterectomy

5. symptomatic AND carotid stenosis AND carotid endarterectomy

\section{WHAT'S NEW}

\begin{tabular}{lll}
\hline Date & Event & Description \\
\hline 23 October 2019 & $\begin{array}{l}\text { New citation required but conclusions } \\
\text { have not changed }\end{array}$ & New first author. Conclusions unchanged. \\
\hline 23 October 2019 & New search has been performed & $\begin{array}{l}\text { We updated the literature searches, including the search of the } \\
\text { Cochrane Stroke Group Trials Register, to October 2019. In the } \\
\text { three years since the previous version of this Cochrane review } \\
\text { was published, no further prospective randomised trials have } \\
\text { been performed, so there are still only three included trials in- } \\
\text { volving 6343 participants. }\end{array}$ \\
\hline
\end{tabular}

\section{H I S T O R Y}

Protocol first published: Issue 2, 1998

Review first published: Issue 3, 1999

\begin{tabular}{lll}
\hline Date & Event & Description \\
\hline 2 August 2016 & New search has been performed & This update was carried out by a new team. \\
\hline
\end{tabular}

Carotid endarterectomy for symptomatic carotid stenosis (Review) 


\begin{tabular}{lll}
\hline Date & Event & Description \\
\hline 28 April 2010 & $\begin{array}{l}\text { New citation required but conclusions } \\
\text { have not changed }\end{array}$ & $\begin{array}{l}\text { This update was undertaken by a new team of authors. We up- } \\
\text { dated the searches to March 2010 and updated the search of } \\
\text { the Cochrane Stroke Group Trials Register to July 2010. In the } \\
11 \text { years since the previous version of this Cochrane review was } \\
\text { published, no further prospective randomised or quasi-ran- } \\
\text { domised trials have been performed. However, we have added } \\
\text { the pooled analysis of individual patient data from the three } \\
\text { largest randomised trials, including subgroup analyses. Although } \\
\text { the qualitative conclusions about the effects of surgery have not } \\
\text { changed since 1999, we have added data on effects in important } \\
\text { categories of patients. }\end{array}$ \\
\end{tabular}

23 July $2008 \quad$ Amended Converted to new review format.

\section{CONTRIBUTIONS OF AUTHORS}

Amaraporn Rerkasem: designed the protocol, performed searches, selected studies for inclusion or exclusion, extracted data and updated the review

Saritphat Orrapin: designed the protocol, performed searches, selected studies for inclusion or exclusion, extracted data and updated the review

Dominic PJ Howard: advised on the design of the protocol, updated the review, extracted data

Kittipan Rerkasem: selected studies for inclusion or exclusion, advised on the design of the protocol, updated the review, extracted data, and locally co-ordinated the update

\section{DECLARATIONS OF INTEREST}

Amaraporn Rerkasem: none known

Saritphat Orrapin: none known

Dominic PJ Howard: none known

Kittipan Rerkasem: none known

\section{SOURCES OF SUPPORT}

\section{Internal sources}

- Host institutes, Other

We thank our host institutes for in-kind support for office space, library, and internet-computer services

\section{External sources}

- No sources of support supplied

\section{N DEX TERMS}

\section{Medical Subject Headings (MeSH)}

Age Factors; Carotid Stenosis [diagnostic imaging] [pathology] [*surgery]; *Endarterectomy, Carotid [adverse effects] [mortality] [standards]; Ischemic Attack, Transient [etiology]; Postoperative Complications [etiology] [ ${ }^{*}$ prevention \& control]; Randomized Controlled Trials as Topic; Risk; Sex Factors; Stroke [etiology] [ ${ }^{\star}$ prevention \& control]; Time Factors

\section{MeSH check words}

Adult; Aged; Female; Humans; Male 